\title{
Assessing the Influence of Microphysical and Environmental Parameter Perturbations on Orographic Precipitation
}

\author{
ANNARELI MORALES \\ University of Michigan, Ann Arbor, Michigan, and National Center of Atmospheric Research, Boulder, Colorado \\ DEREK J. PosSELT \\ Jet Propulsion Laboratory, California Institute of Technology, Pasadena, California \\ HUGH MORRISON \\ National Center of Atmospheric Research, Boulder, Colorado
}

FEI HE

University of California, Los Angeles, Los Angeles, California

(Manuscript received 10 October 2018, in final form 7 February 2019)

\begin{abstract}
Microphysical (MP) schemes contain parameters whose values can impact the amount and location of forecasted precipitation, and sensitivity is typically explored by perturbing one parameter at a time while holding the rest constant. Although much can be learned from these "one-at-a-time" studies, the results are limited as these methods do not allow for nonlinear interactions of multiple perturbed parameters. This study applies the Morris one-at-a-time (MOAT) method, a robust statistical tool allowing for simultaneous perturbation of numerous parameters, to explore orographic precipitation sensitivity to changes in microphysical and environmental parameters within an environment characteristic of an atmospheric river. Results show parameters associated with snow fall speed coefficient $A_{s}$ and density $\rho_{s}$, ice-cloud water collection efficiency (ECI), rain accretion (WRA), relative humidity, zonal wind speed, and surface potential temperature cause the largest influence on simulated precipitation. MP and environmental parameter perturbations can cause precipitation changes of similar magnitude, but results vary by location on the mountain. Different environments are also tested, with $A_{s}$ being the most influential MP parameter regardless of environment. Fewer MP parameters influence precipitation in a faster-wind-speed environment, possibly due to the stronger dynamical forcing upwind and different wave dynamics downwind, compared to a slower-wind-speed environment. Finally, perturbing MP parameters within a single scheme can result in precipitation variations of similar magnitude compared to using entirely different microphysics schemes. MOAT results presented in this study have implications for Bayesian parameter estimation methods and stochastic parameterization within ensemble forecasting.
\end{abstract}

\section{Introduction}

Microphysical parameterizations represent cloud and precipitation processes within numerical weather prediction models used in operational forecasting and research. All schemes contain parameters whose values are known to naturally vary in space and time, yet are typically held constant, for example, snow particle density. These parameter values also have a range of

Corresponding author: Annareli Morales, annareli@umich.edu uncertainty due to limited observations and measuring capabilities, or because the parameter may not have a physical equivalent in nature, for example, autoconversion thresholds. Changes in these parameters have been shown to affect cloud development, as well as precipitation distribution and timing over mountains (e.g., Colle et al. 2005; Jankov et al. 2007, 2009; Liu et al. 2011). For example, reducing the snow particle fall speed, or the degree of riming, can shift maximum precipitation from the windward to lee side of a mountain (Hobbs et al.1973; Colle and Mass 2000; Lin and Colle 2009, 2011; Morrison et al. 2015; 
Morales et al. 2018, hereafter M18). Communities worldwide depend on orographic precipitation for their freshwater resources, thus it is of utmost importance to understand how uncertainty in microphysical parameters may impact where and how much precipitation is forecast to occur.

Colle (2004) was one of the first studies to rigorously explore the sensitivity of orographic precipitation to changes in ambient conditions and mountain geometry. Performing hundreds of two-dimensional (2D) idealized simulations, the study showed the spatial distribution of precipitation was dependent on the flow regime and gravity wave evolution caused by changes to horizontal wind speed and direction. Through the numerous combinations of individual parameter perturbations, this study demonstrated the complex relationships between microphysics, dynamics, and environmental conditions. For example, melting of snow and graupel can lower the freezing level upwind of a mountain range more for a wider and higher barrier in a moderate-wind-speed environment (Colle 2004). Additionally, precipitation distribution response to wind speed changes can vary depending on the height of the freezing level, that is, a lower freezing level can result in decreased upwind precipitation efficiency with increasing wind speed, as faster flow favors the leeside advection of ice (Colle 2004). For a higher freezing level, more efficient warm-rain processes would increase precipitation over the windward slope as less precipitation is advected leeward (Colle 2004; M18).

Motivated by previous studies attributing poor precipitation forecasts to microphysics representation in mesoscale models, Colle and Zeng (2004a) varied parameters within a bulk scheme for an idealized simulation of a 1986 Sierra Nevada precipitation event. They found precipitation to be most sensitive to snow and graupel fall velocities, snow size distribution intercept parameter, and cloud condensation nuclei concentration. A subsequent study by Colle and Zeng (2004b) varied barrier width and freezing levels in addition to microphysical parameters. They found orographic precipitation over wide mountains was most sensitive to snow fall velocity owing to increased time for snow growth before reaching the surface (Colle and Zeng 2004b). Additionally, precipitation sensitivity to microphysics varied for different freezing levels due to different processes being activated. Although an increase in surface temperature led to an increase in available precipitable water, there was a nonlinear effect on precipitation due to different microphysical processes activating at different temperatures and a decrease in the depth over which ice processes occur, resulting in reduced precipitation contribution from melting (Miglietta and Rotunno 2006; Kirshbaum and Smith 2008; M18). Orographic precipitation location and amount can be affected by changes to static stability, wind speed, and mountain height through changes in updraft strength, flow characteristics, and gravity wave dynamics (Durran 1990; Colle 2004; Kunz and Kottmeier 2006; Kunz and Wassermann 2011).

More recently, Tushaus et al. (2015) performed a multivariate sensitivity analysis using Bayesian methods to determine the impact of upwind environment and mountain geometry to orographic precipitation. Their results showed nonunique responses of precipitation rate to changes in mountain half-width, Brunt-Väisälä frequency, and horizontal-wind-speed values, as well as showing multiple combinations of parameters can result in the same precipitation amount and distribution. Tushaus et al. (2015) did not include ice microphysical processes in their study, which are influential to precipitation development and intensity (Castellano et al. 2004; Colle et al. 2005; Purdy et al. 2005; Minder et al. 2008). Ice microphysics adds considerable complexity owing to the numerous processes for ice growth, and the wide variety of ice types and crystal habits. Thus, M18 expanded on previous work by including ice microphysics while testing the effects of microphysical parameter perturbations on orographic precipitation. Their idealized simulations found four dominant parameters were responsible for the largest changes in precipitation rate and liquid and ice water paths: snow fall speed coefficient, snow particle density, rain accretion, and ice-snow collection efficiency. Overall, M18 found changes to environmental parameters (i.e., wind speed and surface temperature) were largely responsible for the total amount of available condensate for the microphysics to act upon, and affected which microphysical processes were dominant (i.e., warm rain versus ice).

These previous studies suggest complex relationships between microphysics and the upstream environment, that is, microphysical parameter sensitivities can change with different environments, perturbations to environmental conditions can result in nonlinear responses, etc. However, most model parameter sensitivity studies on orographic precipitation perturb one parameter at a time while holding the rest constant, also known as having a constant "base state." This method for sensitivity analysis is inherently limited, and if relationships among parameters are nonlinear, may result in incomplete conclusions. On the other hand, quantifying multiparameter sensitivity is challenging because the number of simulations required is equal to $M^{N}$, where $M$ is the number of values tested per parameter and $N$ is the number of parameters. As microphysical parameterizations have become more complex, the number of "tunable" parameters have increased. Thus, brute-force calculation 
of multiparameter sensitivity in the large-dimensional parameter space is not generally computationally feasible.

To address this problem, we employ the Morris one-ata-time (MOAT) method, which explores interactions between parameters through multivariate parameter perturbations (Morris 1991; Campolongo et al. 2007). MOAT can test a large number of parameter combinations and isolate the influences of individual parameters on model output (Saltelli et al. 2008). This statistically robust method has been widely used for hydrologic model sensitivity analysis (King and Perera 2013; Shin et al. 2013; Yang et al. 2014; Song et al. 2015) but has been infrequently applied to atmospheric science. Covey et al. (2013) introduced this method to the climate science community in a study that explored the sensitivity of outgoing longwave and shortwave radiation to various climate model input parameters in the Community Atmospheric Model; while Zhang et al. (2015) used MOAT for parameter sensitivity analysis in the Grid-Point Atmospheric Model. Most recently, Zarzycki and Ullrich (2017) applied MOAT to investigate the sensitivity of "objectively tracked output metrics," for example, accumulated cyclone energy and false alarm rate, in climate model data to various tropical cyclone tracking algorithm parameters. To our knowledge, the study described herein is the first to use MOAT to analyze simulations of orographic precipitation.

Our study focuses on understanding simulated precipitation sensitivities for moist, nearly neutral flow over a 2D bell-shaped mountain. This type of flow is commonly found within wintertime atmospheric rivers (ARs) off the western U.S. coast and allows for little resistance to orographic lift, causing enhanced precipitation over windward mountain slopes (Lin et al. 2001; Ralph et al. 2004, 2005; Neiman et al. 2011; Ralph and Dettinger 2011). This AR-produced precipitation is responsible for up to $50 \%$ of California's annual precipitation (Dettinger et al. 2011) and can lead to flash floods and landslides (Ralph et al. 2006).

Given the importance of both microphysics and environmental conditions to orographic precipitation, this study explores the following science questions:

- Which microphysical parameters are most influential to orographic precipitation when multiparameter interactions are allowed?

- How are microphysical parameter sensitivities changed when environmental parameters are perturbed simultaneously for a given environmental state?

- Are the effects from microphysical parameter perturbations larger than the effects of environmental parameter uncertainty?
- How does the influence of microphysical parameter perturbations change when different environments are imposed?

- Are the effects from microphysical parameter perturbations in a single scheme larger than the effects caused by using different microphysical schemes?

We hypothesize that both microphysical and environmental parameters will be important; that is, perturbations to microphysical parameters will cause a change in the model output comparable to that from small perturbations to the environmental state, over ranges of parameter uncertainty for both. We also expect that sensitivity to microphysical parameter perturbations will vary depending on the environmental state, regardless of multiparameter perturbations allowed in MOAT, since changes to environmental conditions have been shown to be responsible for the total amount of condensate produced (M18).

The model configuration and experimental design, as well as a brief description of the MOAT algorithm, are provided in section 2. Results from the sensitivity analysis are presented and discussed in section 3, with section 4 providing a summary and conclusions.

\section{Methods}

\section{a. Model configuration}

All experiments are performed using version 17 of Cloud Model 1 (CM1), a nonhydrostatic numerical model often used for idealized simulations of cloudscale processes (Bryan and Fritsch 2002). The model configuration follows that of M18, thus only a brief summary will be provided here.

A 2D domain of $1600 \mathrm{~km}$ in length is used. The inner domain is $1200 \mathrm{~km}$ in length, spanning over 600 grid points, with a horizontal grid spacing of $2 \mathrm{~km}$ that stretches to $6 \mathrm{~km}$ over 50 grid points on each side. The mountain center is shifted $400 \mathrm{~km}$ downstream to limit the reflection of waves from the upwind boundary. Total domain height is $18 \mathrm{~km}$ with 55 vertical levels. The vertical grid spacing $\Delta z$ is $0.25 \mathrm{~km}$ below a height of $9 \mathrm{~km}$, and stretches to $0.5 \mathrm{~km}$ up to $10.5 \mathrm{~km}$, after which $\Delta z$ remains constant at $0.5 \mathrm{~km}$. Lateral boundaries are openradiative and the bottom boundary condition is no-slip. Radiation, surface fluxes, and Coriolis acceleration are neglected. Simulations are run for $20 \mathrm{~h}$ using a 3-s time step. A Gaussian bell-shaped mountain with a $2-\mathrm{km}$ height and 40-km half-width is used. Note, the mountain height used here is twice the size of that used in M18. These mountain shape parameters are characteristic of the Sierra Nevada and Cascade mountains, which have 


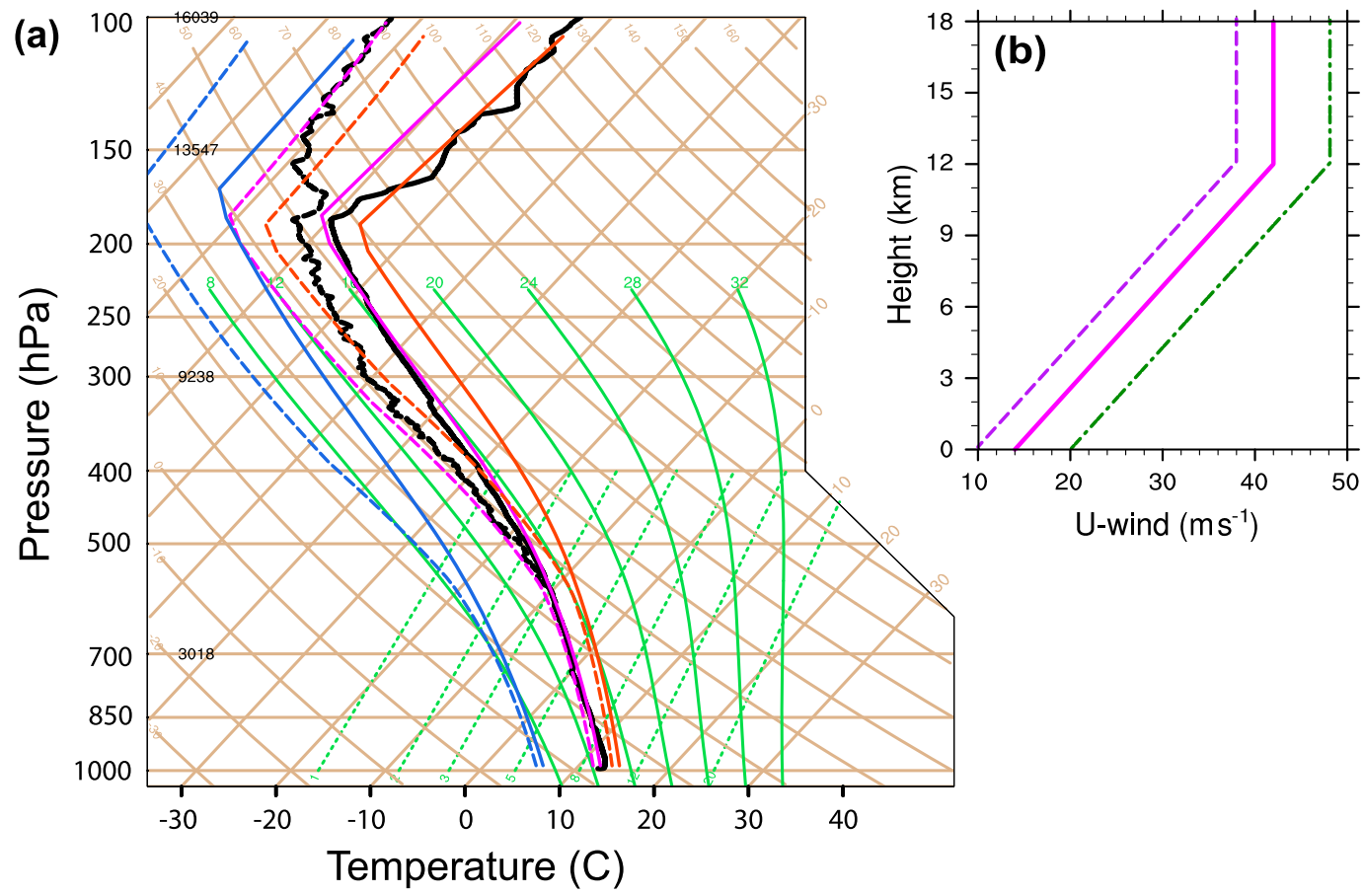

FIG. 1. (a) Skew $T$ diagram showing the observed sounding from OLYMPEX at 0300 UTC 13 Nov 2015 (black), idealized sounding (magenta), MP_COLD sounding (blue), and MP_WARM sounding (orange). For all soundings, solid lines represent temperature $\left({ }^{\circ} \mathrm{C}\right)$ and dashed lines represent dewpoint temperature $\left({ }^{\circ} \mathrm{C}\right)$. (b) Vertical profile of zonal wind speed $\left(\mathrm{m} \mathrm{s}^{-1}\right)$ showing the idealized profile (solid magenta), MP_SLOW profile (dashed purple), and MP_FAST profile (dot-dashed green).

been idealized as $2 \mathrm{D}$ ridges in previous studies (e.g., Colle and Zeng 2004a,b; Colle 2004; Kirshbaum and Smith 2008). Limitations do exist when using a $2 \mathrm{D}$ domain, for example overamplification of mountain waves due to energy dispersion limited to one direction, unrealistic mountain profiles, and reduced deflection of low-level flow. A 2D model configuration is applied as it simplifies the number of parameters controlling the upstream flow, allowing for a more controlled set of experiments. We thus follow past studies which have applied a 2D domain to study mountain flow dynamics and orographic precipitation (e.g., Doyle et al. 2000; Colle 2004; Colle and Zeng 2004a,b; Miglietta and Rotunno 2005, 2006; Tushaus et al. 2015; M18).

The idealized control sounding and wind speed profile (Fig. 1) is the same as in M18, and closely corresponds to conditions observed during atmospheric river events for OLYMPEX (Houze et al. 2017) and other field campaigns (e.g., Ralph et al. 2005). The atmospheric profile is described by the following default values: a surface potential temperature $\theta_{\text {sfc }}$ of $286 \mathrm{~K}$; surface $u$-wind speed $U$ of $14 \mathrm{~m} \mathrm{~s}^{-1}$, linearly increasing to $42 \mathrm{~m} \mathrm{~s}^{-1}$ at a height of $12 \mathrm{~km}$, then remaining constant at $42 \mathrm{~m} \mathrm{~s}^{-1}$ above $12 \mathrm{~km}$; relative humidity $(\mathrm{RH})$ below $4.5 \mathrm{~km}$ of $95 \%$, then linearly decreasing to $20 \%$ at a height of $16 \mathrm{~km}$, and remaining constant above $16 \mathrm{~km}$; and a moist Brunt-Väisälä frequency $N_{m}^{2}$ for the troposphere and stratosphere of $4 \times 10^{-5}$ and $5 \times 10^{-4} \mathrm{~s}^{-2}$, respectively.

\section{b. Microphysical and environmental parameters}

The Morrison two-moment microphysics scheme, version 3.4 (Morrison et al. 2005, 2009), is used, with the rimed ice species set to graupel. Microphysical parameters and their uncertainty ranges are the same as those listed in M18. The microphysical parameters examined focus on prescribed parameters for frozen condensate, conversion thresholds, collection efficiencies, and ice processes within the Morrison scheme (Table 1). Because there are few prescribed parameters for warm-rain processes, we apply a multiplicative factor for rain accretion and autoconversion. The range of values used to perturb the parameters is based on our estimate of uncertainty and variability for each microphysical parameter. As described in the introduction, previous studies have found $\theta_{\mathrm{sfc}}, \mathrm{RH}$, tropospheric $N_{m}^{2}$, and $U$ impact orographic cloud and precipitation development through condensate production and advection, freezing-level effects, and changes to the vertical velocities. To understand the influence of environmental parameter perturbations on microphysical parameter sensitivities, and compare the effects on precipitation when both 
TABLE 1. Input parameters varied in MOAT experiments.

\begin{tabular}{rlc}
\hline \hline$j$ & \multicolumn{1}{c}{ Parameter description (symbol) } & Uncertainty range \\
\hline 1 & Cloud ice fall speed coefficient $\left(A_{i}\right)$ & $700 \mathrm{~m}^{(1-b)} \mathrm{s}^{-1} \pm 50 \%$ \\
2 & Snow fall speed coefficient $\left(A_{s}\right)$ & $11.72 \mathrm{~m}^{(1-b)} \mathrm{s}^{-1} \pm 50 \%$ \\
3 & Graupel fall speed coefficient $\left(A_{g}\right)$ & $19.3 \mathrm{~m}^{(1-b)} \mathrm{s}^{-1} \pm 50 \%$ \\
4 & Cloud ice density $\left(\rho_{i}\right)$ & $500 \mathrm{~kg} \mathrm{~m}^{-3} \pm 50 \%$ \\
5 & Snow density $\left(\rho_{s}\right)$ & $100 \mathrm{~kg} \mathrm{~m}^{-3} \pm 50 \%$ \\
6 & Graupel density $\left(\rho_{g}\right)$ & $400 \mathrm{~kg} \mathrm{~m}^{-3} \pm 50 \%$ \\
7 & Cloud ice autoconversion threshold (DCS) & $125 \mu \mathrm{m} \pm 50 \%$ \\
8 & Nucleated ice crystal radius (RMI0) & $1-30 \mu \mathrm{m}$ \\
9 & Embryo graupel radius (RMG0) & $35-1000 \mu \mathrm{m}$ \\
10 & Ice-ice collection efficiency (EII) & $0.01-1$ \\
11 & Ice-cloud water collection efficiency (ECI) & $0.3-1$ \\
12 & Radius of splintered ice particle (RMMULT) & $1-30 \mu \mathrm{m}$ \\
13 & Rain accretion multiplicative factor (WRA) & $0.5-2$ \\
14 & Cloud water autoconversion multiplicative factor (WRC) & $0.1-10$ \\
15 & Snow deposition multiplicative factor (SDEP) & $0.5-2$ \\
16 & Relative humidity profile additive factor (RH) & $\pm 10 \%$ \\
17 & $u$-wind speed profile additive factor $(U)$ & $\pm 1 \mathrm{~m} \mathrm{~s}$ \\
18 & Surface potential temperature $\left(\theta_{\text {sfc }}\right)$ & $285-287 \mathrm{~K}$ \\
19 & Tropospheric moist Brunt-Väisälä frequency additive factor $\left(N_{m}^{2}\right)$ & $\pm 2.5 \times 10^{-6} \mathrm{~s}^{-2}$ \\
\hline
\end{tabular}

groups of parameters are perturbed, we use a range of values consistent with the relative uncertainty of observations. For example, we assume the average uncertainty for $\theta_{\text {sfc }}$ in a sounding is $1 \mathrm{~K}$, thus our uncertainty range is $\pm 1 \mathrm{~K}$ from the default surface potential temperature of $286 \mathrm{~K}$ (Table 1). The $\mathrm{RH}, N_{m}^{2}$, and $U$ parameters are perturbed using "additive factors," which act to increase/ decrease the value for that parameter in the module. To determine the $N_{m}^{2}$ change for a potential temperature perturbation of $1 \mathrm{~K}$, Eq. (36) from Durran and Klemp (1982) is used to calculate a range of uncertainty $\pm 2.5 \times$ $10^{-6} \mathrm{~s}^{-2}$ from the default tropospheric moist BruntVäisälä frequency. The additive factors for $U$ and $\mathrm{RH}$ act to shift the wind speed and relative humidity profiles, respectively, to higher or lower values. The additive factor for wind speed is given a typical uncertainty range for a sounding of $\pm 1 \mathrm{~m} \mathrm{~s}^{-1}$, thus the control wind profile is perturbed within this narrow range of values. Last, the additive factor for $\mathrm{RH}$ is assumed to have an uncertainty of $\pm 10 \%$ for a sounding. To avoid having a saturated upstream environment before the flow encounters the barrier, the maximum value of surface $\mathrm{RH}$ is $99 \%$. Because the control profile has a surface $\mathrm{RH}$ at $95 \%$ and the profile below $16 \mathrm{~km}$ depends on the surface $\mathrm{RH}$ value, this region has an uncertainty range between $-10 \%$ and $4 \%$. Above a height of $16 \mathrm{~km}$ it is allowed to increase up to $10 \%$. Thus, the range of RH values in our sensitivity tests is $85 \%-99 \%$ below $4.5 \mathrm{~km}$ and $10 \%-30 \%$ above $16 \mathrm{~km}$.

Analysis of precipitation rate, total condensation rate, and precipitation efficiency is performed using 5-min model output temporally averaged between hours 6 and 20, during which the cross-mountain flow, precipitation rate, and cloud and hydrometeor development are relatively steady (Fig. 2). We spatially average model output over six locations on the mountain: upwind foothills (UF), slope (US), and top (UT) and downwind foothills (DF), slope (DS), and top (DT) (Fig. 2c). Total condensation rate ( $\langle\mathrm{COND}\rangle$; $\left.\mathrm{mm} \mathrm{h}^{-1}\right)$ is a vertical integral of all process rates that convert water vapor to condensate, and is subsequently horizontally averaged over the six mountain regions (M18). Precipitation efficiency (PE) is calculated as $\mathrm{PE}=$ PREC $/\langle C O N D\rangle$, where PREC is the horizontally averaged total (liquid + frozen) precipitation rate over the six regions, and quantifies the fraction of condensate removed through microphysical processes (evaporation and sublimation) and sedimentation. PE can also be affected by horizontal transport of condensate because of the spatial averaging performed over limited regions of the domain. This analysis provides information on whether a parameter's influence on PREC is due to that parameter effecting dynamical-thermodynamical processes $(\langle\mathrm{COND}\rangle)$ and/or microphysical processes and sedimentation (PE).

\section{c. Experimental design}

The MOAT method is used to determine which subset of microphysical and environmental parameters results in the largest changes to surface precipitation. To understand how simultaneously perturbing microphysical and environmental parameters impacts precipitation sensitivities, experiment "MP_ENV" is performed and compared to "MultiParam," which perturbs multiple microphysical parameters using MOAT while keeping the environment constant (Table 2). It is known 

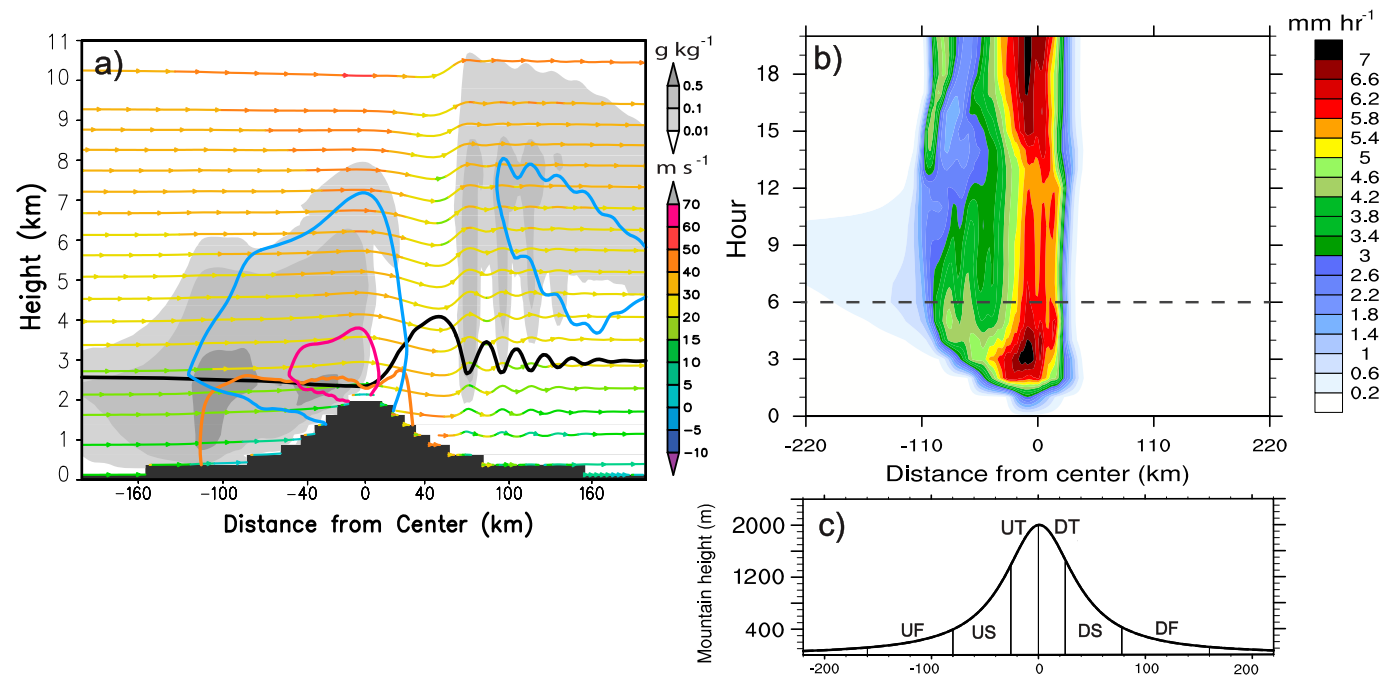

FIG. 2. (a) Vertical cross section showing temporally averaged (hours 6-20) streamlines with wind speed (colored shading; $\mathrm{m} \mathrm{s}^{-1}$ ), freezing level (black line), cloud water and ice mixing ratios (gray shading; $\mathrm{g} \mathrm{kg}^{-1}$ ), and $0.05 \mathrm{~g} \mathrm{~kg}^{-1}$ mixing ratio contours for snow (blue), rain (orange), and graupel (magenta) for the control simulation over a portion of the domain. (b) Hovmöller diagram of precipitation rate $\left(\mathrm{mm} \mathrm{h}^{-1}\right)$ with simulation time on the ordinate and distance from the center of the mountain on the abscissa. The dashed line corresponds to hour 6 , the start of temporal averaging. (c) Mountain height $(\mathrm{m})$ profile with the six averaging regions used for the calculations: upwind foothills (UF), slope (US), top (UT), and downwind top (DT), slope (DS), and foothills (DF).

that upstream conditions can vary the precipitation sensitivity to microphysical parameter perturbations (Colle and Zeng 2004b; Miglietta and Rotunno 2006; M18), thus we perform a second set of experiments to test if these previous findings still hold when multiparameter perturbations are included using MOAT. We expand on M18 and test four environments corresponding to a colder (MP_COLD), warmer (MP_WARM), slower-wind-speed (MP_SLOW), or faster-wind-speed (MP_FAST) environment.

MP_COLD decreases the control temperature profile by $6 \mathrm{~K}\left(\theta_{\mathrm{sfc}}=280 \mathrm{~K}\right.$; Fig. 1a), thus simulating an environment where much of the upwind slope and mountaintop are above the freezing level and upon which most precipitation falls as snow. This case should exhibit greater dominance of ice processes, since a larger amount of the cloud occurs above the $0^{\circ} \mathrm{C}$ level, and there will be less available precipitable water owing to the decrease in temperature. MP_WARM increases the control temperature profile by $2 \mathrm{~K}\left(\theta_{\mathrm{sfc}}=288 \mathrm{~K}\right.$; Fig. 1a) and thus has a deeper melting layer where warm-rain processes dominate and a larger fraction of the precipitation falls as rain. Because RH is held constant, increased water vapor content due to increased temperatures is expected to increase total precipitation. MP_SLOW decreases the wind speed profile by $4 \mathrm{~m} \mathrm{~s}^{-1}$, resulting in a surface wind speed of $10 \mathrm{~m} \mathrm{~s}^{-1}$ (Fig. 1b). MP_FAST increases the wind speed profile by $6 \mathrm{~m} \mathrm{~s}^{-1}$, resulting in a surface wind speed of $20 \mathrm{~m} \mathrm{~s}^{-1}$ (Fig. 1b). This case acts to simulate a low-level jet, which has been observed below $2 \mathrm{~km}$ MSL during AR events (Ralph et al. 2005), impinging on the barrier. Given a strong cross-barrier flow, we expect more downwind transport as well as more condensation upwind caused by stronger vertical velocities relative to the control environment.

Finally, experiments are performed in which the entire microphysics scheme is changed rather than individual parameters within a single scheme (MultiPhys) to compare the sensitivity of surface precipitation to different microphysics schemes. In addition to the Morrison two-moment scheme used for the MOAT experiments, the Thompson (Thompson et al. 2008), NASA Goddard LFO (Gilmore et al. 2004), and NSSL two-moment (Ziegler 1985; Mansell et al. 2010; Mansell 2010) schemes are used for the "ensemble" used in MultiPhys. The same four schemes are tested with the upstream soundings used for MP_COLD, MP_WARM, MP_SLOW, and MP_FAST to account for possible sensitivity to the environment. A summary of all the experiments is listed in Table 2 .

\section{d. MOAT method}

As described in section 1, previous studies have performed sensitivity analysis on microphysical and environmental parameters by perturbing each parameter of interest individually while holding the rest constant, that 
TABLE 2. List of experiments.

\begin{tabular}{|c|c|c|}
\hline Experiment & Description & Purpose \\
\hline MultiParam & $\begin{array}{l}\text { Multiple microphysical parameters perturbed using } \\
\text { MOAT; environmental parameters held constant } \\
\text { at default values }\end{array}$ & $\begin{array}{l}\text { Building on M18 by allowing for multiparameter } \\
\text { interactions using MOAT }\end{array}$ \\
\hline MP_ENV & $\begin{array}{l}\text { Microphysical and environmental parameters } \\
\text { perturbed simultaneously using MOAT }\end{array}$ & Testing the influence of microphysics vs environment \\
\hline MP_COLD & $\begin{array}{l}\text { Multiple microphysical parameters perturbed using } \\
\text { MOAT; surface potential temperature default } \\
\text { value decreased by } 6 \mathrm{~K}\left(\theta_{\mathrm{sfc}}=280 \mathrm{~K}\right)\end{array}$ & $\begin{array}{l}\text { Testing microphysical parameter sensitivities in a } \\
\text { low-freezing-level environment }\end{array}$ \\
\hline MP_WARM & $\begin{array}{l}\text { Multiple microphysical parameters perturbed using } \\
\text { MOAT; surface potential temperature default } \\
\text { value increased by } 2 \mathrm{~K}\left(\theta_{\text {sfc }}=288 \mathrm{~K}\right)\end{array}$ & $\begin{array}{l}\text { Testing microphysical parameter sensitivities in a } \\
\text { higher-freezing-level environment }\end{array}$ \\
\hline MP_SLOW & $\begin{array}{l}\text { Multiple microphysical parameters perturbed using } \\
\text { MOAT; zonal wind speed profile decreased by } \\
4 \mathrm{~m} \mathrm{~s}^{-1}\left(U_{\mathrm{sfc}}=10 \mathrm{~m} \mathrm{~s}^{-1}\right)\end{array}$ & $\begin{array}{l}\text { Testing microphysical parameter sensitivities in an } \\
\text { environment with weaker dynamics }\end{array}$ \\
\hline MP_FAST & $\begin{array}{l}\text { Multiple microphysical parameters perturbed using } \\
\text { MOAT; zonal wind speed profile increased by } \\
6 \mathrm{~m} \mathrm{~s}^{-1}\left(U_{\mathrm{sfc}}=20 \mathrm{~m} \mathrm{~s}^{-1}\right)\end{array}$ & $\begin{array}{l}\text { Testing microphysical parameter sensitivities in an } \\
\text { environment with stronger dynamics }\end{array}$ \\
\hline MultiPhys & $\begin{array}{l}\text { An "ensemble" (four simulations total) using } \\
\text { different microphysical schemes (Morrison two- } \\
\text { moment, Thompson, NSSL two-moment, and NASA } \\
\text { Goddard LFO); no changes to default environmental } \\
\text { or microphysical parameters in any schemes }\end{array}$ & $\begin{array}{l}\text { Comparing the influence of using different schemes } \\
\text { to parameter perturbations within a single scheme }\end{array}$ \\
\hline
\end{tabular}

is, a "constant base state." This type of single parameter perturbation may miss interactions with other parameters. Therefore, the MOAT method, also known as the Morris screening or Elementary Effects method, is used to determine the input factors that have the largest influence on the model output when considering multivariate parameter perturbations (Morris 1991; Campolongo et al. 2007).

MOAT allows for simultaneous testing of a large number of input parameters while being computationally affordable, that is, $M(N+1)$ simulations are required for $N$ input parameters and $M$ trajectories or paths, compared to $M^{N}$ for a standard multiparameter sensitivity analysis. Although MOAT allows for nonlinearity and interaction effects, is computational efficient, and its results are straightforward to understand, this method only provides a qualitative sensitivity analysis. For example, while it can be used to rank the influence of parameters and determine whether there is nonlinearity in the input-output relationship, it cannot be used to compute the fraction of the variance in model output explained by each parameter, or combinations of multiple parameters. For a quantitative analysis that can provide deeper understanding of nonlinear parameter interactions and determine individual parameters' contribution to the output variance, more computationally expensive variance-based methods must be applied (Saltelli et al. 2008). MOAT is commonly used as a first step toward variance-based analysis, as it identifies which parameters are influential, allowing a smaller subset to be explored using more computationally expensive methods.

MOAT provides a sensitivity analysis by perturbing individual input parameters with respect to different parameter base states. The values for each input parameter are randomly chosen from a range of values encompassing the parameter uncertainty and/or variability (see Table 1). For a set of parameters $X=$ $x_{1}, x_{2}, \ldots, x_{N}$ the "elementary effect" of the $j$ th parameter is defined as

$$
d_{j}=\frac{y\left(x_{1}, \ldots, x_{j}+\Delta, \ldots, x_{N}\right)-y\left(x_{1}, \ldots, x_{j}, \ldots, x_{N}\right)}{\Delta}
$$

where $y$ represents the model output and $\Delta$ represents a discrete change in the value of parameter $j$ relative to the range (Covey et al. 2013). These variables are normalized to a range of $[0,1]$ before each initial parameter set is generated, to avoid issues comparing parameters with different units. The elementary effect basically calculates the change in the model output, that is, surface precipitation rate, given a change in the input parameter. This process is repeated for $M$ paths within the parameter space, where each path uses a different randomly generated base state. Here we apply the algorithm $M=20$ times, resulting in a total of 320 simulations. Tests showed the results for this study generally converge after $M=15$, thus we believe 20 MOAT paths is sufficient as suggested by Covey et al. (2013). From this distribution of elementary 
effects, the mean of the absolute value of the elementary effects $\mu_{j}^{*}$ (Campolongo et al. 2007) and the standard deviation of the elementary effects $\sigma_{j}$ are calculated as follows:

$$
\begin{aligned}
\mu_{j}^{*} & =\frac{1}{M} \sum_{i=1}^{M}\left|d_{i, j}\right|, \\
\sigma_{j} & =\sqrt{\frac{1}{M} \sum_{i=1}^{M}\left(d_{i, j}-\frac{1}{M} \sum_{i=1}^{M} d_{i, j}\right)^{2}},
\end{aligned}
$$

The average influence of the input parameter on the model output is given by $\mu_{j}^{*}$ and the nonlinearity is determined by $\sigma_{j}$. If $\mu_{j}^{*}$ is large, this means the input parameter caused a large change in the model output, that is, it is an influential/important parameter. If $\sigma_{j}$ is large, or large relative to its corresponding $\mu_{j}^{*}$, this means a perturbation to the input parameter resulted in a large variety of output values caused by nonlinear interactions with other parameters or a nonlinear individual response. Parameters with low $\mu_{j}^{*}$ and $\sigma_{j}$ are noninfluential, implying they could be set to a constant value in the model. These two sensitivity measures can be further used to rank the most influential parameters (high to low $\mu_{j}^{*}$ ), as well as calculate sensitivity characteristics like monotonicity of the response. In the following section, we use fractional sensitivity (FS) to understand the influence of the input parameters on precipitation rate over the six averaging regions of the domain. FS normalizes $\mu_{j}^{*}$ by the model output range $\left(y_{\max }-y_{\min }\right)$ to compare the variation caused by individual parameters to the variation generated from all the one-at-a-time simulations:

$$
\mathrm{FS}=\frac{\mu_{j}^{*}}{y_{\text {max }}-y_{\text {min }}} \times 100 .
$$

For a more detailed description of MOAT and a stepby-step example of how the algorithm is applied, see section 2.2 in Covey et al. (2013).

\section{Results and discussion}

\section{a. Control simulation}

Temporally averaged results for the analysis period (hours 6-20) show the control simulation is characterized by a deep mixed-phase cloud over the upwind mountain side and an upper-level ice cloud downwind (Fig. 2a). Snow extends from a height of $7 \mathrm{~km}$ to below the freezing level upwind, where it reaches the surface over the mountaintop, but melts into rain over UF, US, and DT (Fig. 2a). Rain formed through warm-rain processes exists mainly over UF and US. Graupel forms over the top of the mountain and upwind slope, where vertical velocities are strong enough to sustain growth of rimed ice hydrometeors, and plenty of cloud water is available within supercooled cloud regions. The freezing level lowers toward the mountain, but does not actually intersect the mountain. As the flow descends on the lee side of the mountain, the wind speed increases by approximately $20 \mathrm{~m} \mathrm{~s}^{-1}$ and the freezing level rises to a height of approximately $4 \mathrm{~km}$, caused by adiabatic warming. Trapped lee waves develop, with narrow upward motion strong enough to generate clouds and snow, but no surface precipitation (Fig. 2). In general, the flow follows the terrain and contains no wavebreaking or blocked flow upstream.

A Hovmöller diagram of precipitation rate shows an initial maximum over UT caused by rapid graupel development, fallout, and melting, followed by relatively steadier precipitation and a secondary period of intense precipitation (Fig. 2b). Frozen precipitation (snow and graupel) reaches the surface within a narrow region centered over the mountain peak, while liquid precipitation extends to UF/US and DT, caused by melting of snow and advected rain (not shown). To avoid the 0-6-h model spinup period and gain a broader perspective of the effects caused by multiparameter perturbations, our analysis is focused on hours 6-20, where the condensate development, and flow are relatively steady (Fig. 2a).

A brief comparison of the control simulation in this study and that of M18 shows the difference caused by the increased mountain height. The taller mountain height $(2 \mathrm{~km})$ used in this study generates stronger vertical velocities that are able to sustain graupel development during hours 6-20 and produce higher PREC over the mountaintop. In contrast, the control simulation in M18 with a $1 \mathrm{~km}$ mountain height had a PREC maximum over US and no graupel during hours 6-20.

\section{b. Microphysical and environmental parameter perturbations}

We first discuss which microphysical parameters are most influential to PREC when the environmental conditions are held constant within the control sounding based on the MultiParam MOAT experiment. Figure 3 shows the $\mu_{j}^{*}-\sigma_{j}$ plots with each parameter color coded and labeled. The MultiParam results show the largest effects on PREC occur over the upwind slope and top (Figs. 3b,c), and are caused by changes to the snow fall speed coefficient $A_{s}$ and density $\rho_{s}$, 

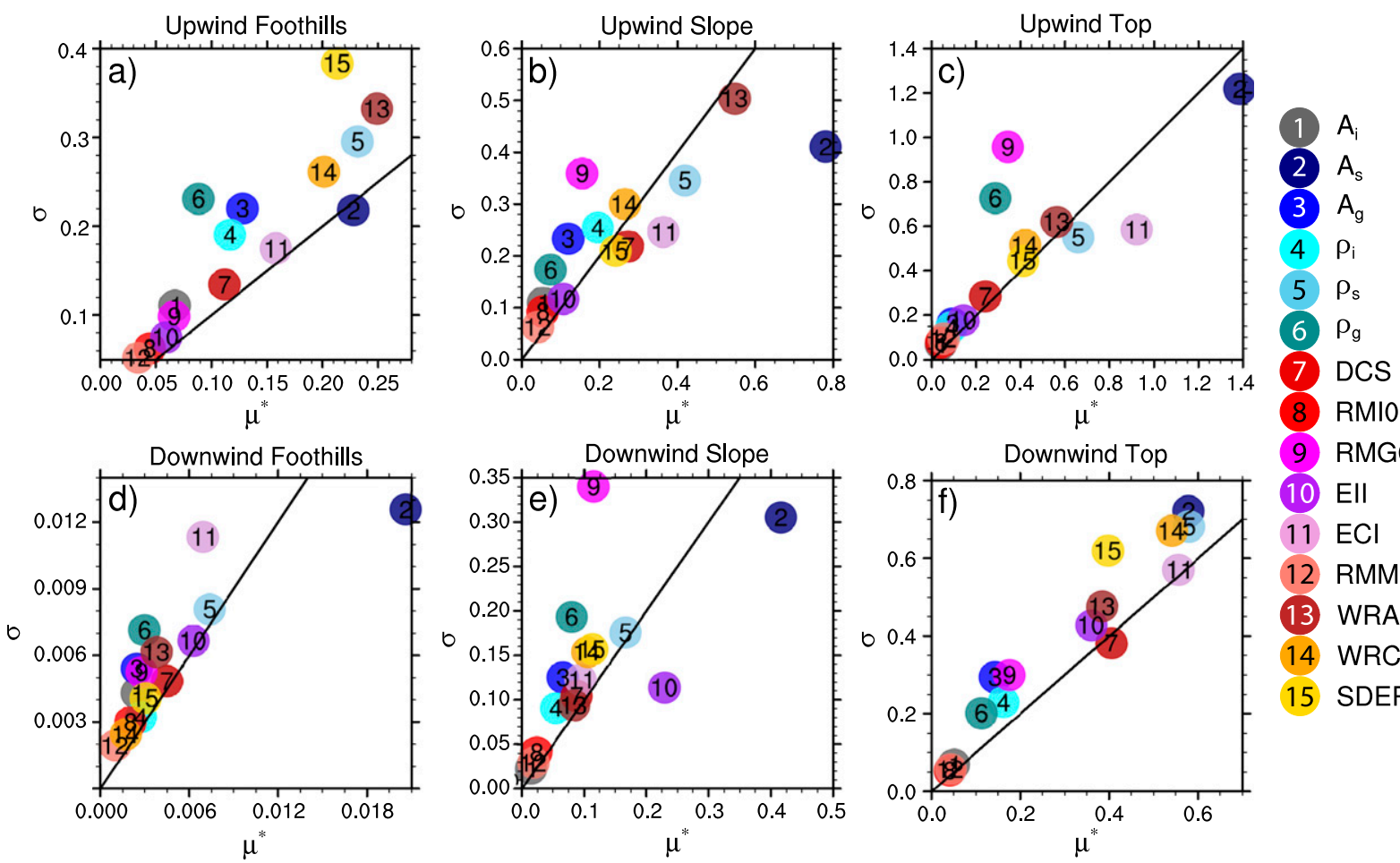

(9) RMG0

10 EII

$11 \mathrm{ECl}$

12 RMMULT

13 WRA

14 WRC

15 SDEP

FIG. 3. Mean magnitude $\mu_{j}^{*}$ and standard deviation $\sigma_{j}$ for total precipitation rate $\left(\mathrm{mm} \mathrm{h}^{-1}\right)$ given 15 microphysical parameters varied using the MOAT screening method for the control environment (MultiParam). Labels $j=1-15$ correspond to the parameters listed in Table 1. Results are temporally and spatially averaged over the six locations on the mountain: (a) upwind foothills, (b) upwind slope, (c) upwind top, (d) downwind foothills, (e) downwind slope, and (f) downwind top. The one-to-one line (solid black) is shown in each panel for reference.

ice-cloud water collection efficiency (ECI), and rain accretion multiplicative factor (WRA). Notably, these parameters are the same as those identified by M18 as influential based on one-at-a-time individual parameter perturbations. Ranking the parameters from highest to lowest $\mu_{j}^{*}$ shows that $A_{s}$ is ranked most important over more locations on the mountain than any other parameter (Fig. 4a). In addition to having a large influence on PREC, the use of MOAT shows that $A_{s}$ has nonlinear parameter interactions (i.e., large $\sigma$ ). This means there are a variety of elementary effects from changes to $A_{s}$, seemingly as a result of interactions with other parameters. Coefficient $A_{s}$ acts to directly affect the snow fall speed and thus impacts existing snow aloft. The large variability in PREC responses to $A_{s}$ is understandable, because various microphysical parameters and processes can impact how much snow is generated for $A_{s}$ to subsequently act upon. Although not as highly ranked, $\rho_{s}$ is also influential over all regions on the mountain. M18 found this parameter caused an unphysical indirect impact on snow fall speeds through interactions with the particle size distribution. WRA is highest ranked over the upwind foothills and slope (Fig. 4a). This is expected, as these locations have large amounts of cloud water and a deep melting layer creating a favorable environment for rain accretion (Fig. 2a). Results also show that ECI and ice-ice collection efficiency (EII) are ranked highly over regions that would have cloud ice and supercooled water, respectively. Thus, the microphysical parameters' influence on PREC can vary spatially, depending on the specific processes dominating over a particular region. Normalizing the rankings by the range of PREC ( $\max -$ min computed per spatial region) generated from all simulations performed using MOAT gives us the fractional sensitivity of each parameter [Eq. (4)]. Parameters with the highest fractional sensitivities are $A_{s}$ and WRA (Fig. 4b). This means that perturbations to $A_{s}$ and WRA produce variability in PREC that is $30 \%-50 \%$ as large as the total variation in PREC.

Next, we describe the MOAT experiment MP_ENV that simultaneously perturbs microphysical and environmental parameters, testing the influence of environmental parameter uncertainty on PREC sensitivities to microphysics. The MP_ENV results show that perturbations to environmental parameters cause a larger 


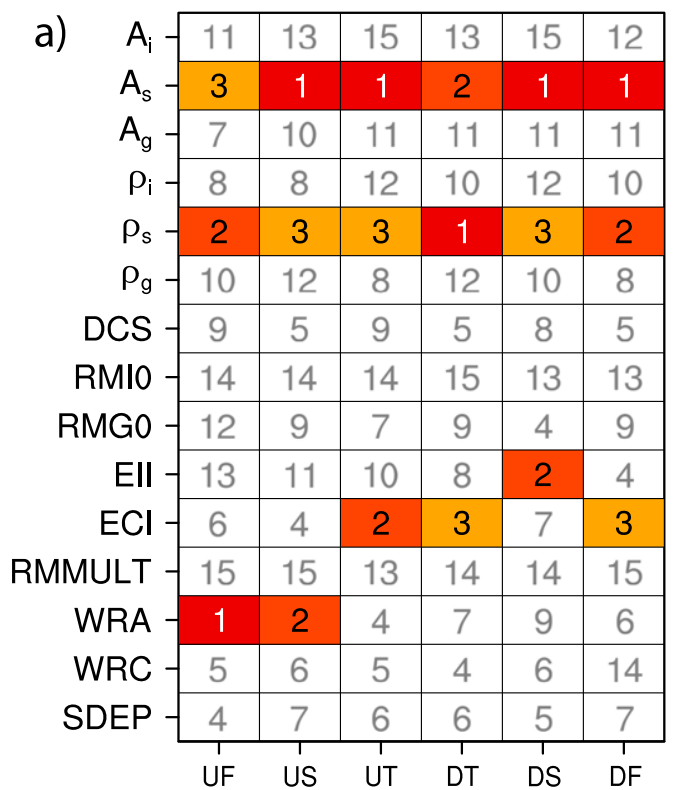

b)

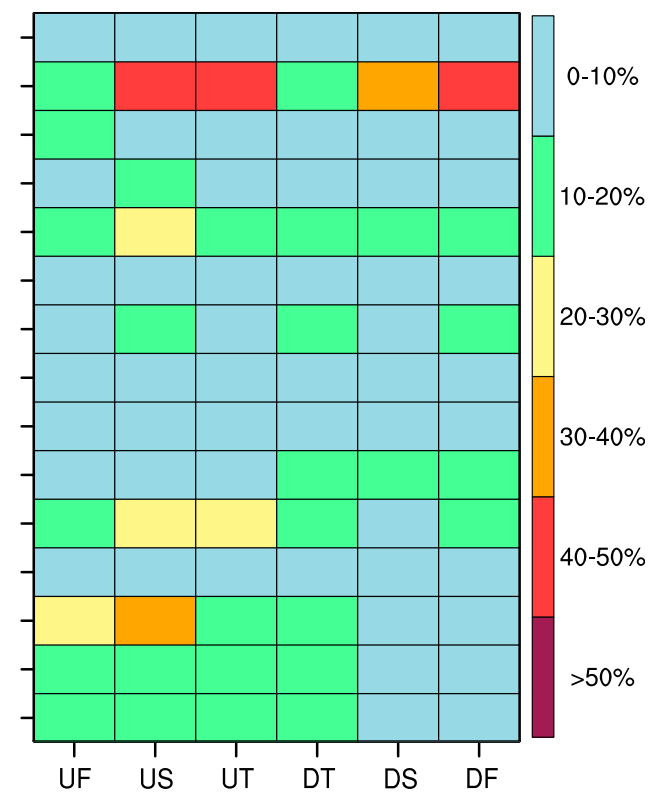

FIG. 4. (a) Ranking of precipitation-rate $\left(\mathrm{mm} \mathrm{h}^{-1}\right)$ sensitivity to parameters for MultiParam. Rank 1 represents the largest $\mu_{j}^{*}$ value, while rank 15 or 19 represents the smallest $\mu_{j}^{*}$ value, for the simulations. Rows are the input parameters described in Table 1 and columns show results for each region over the mountain. (b) Fractional sensitivity (\%) of precipitation rate $\left(\mathrm{mm} \mathrm{h}^{-1}\right)$ to parameters for MultiParam. Rows are input parameters described in Table 1 and columns show each region over the mountain.

change in PREC than microphysical parameter perturbations alone, mainly over regions UF, US, and DT (Fig. 5). This is because changes in the environment affect the amount of moisture available, the resistance to vertical motion, and/or the type of precipitation that develops. Over the UF, US, and DT regions, perturbations to the $\mathrm{RH}$ result in the largest effects on PREC, while perturbations to RH and $A_{s}$ have similar magnitudes of $\mu^{*}$ over UT (Fig. 5). These results show that although the environment does dominate the formation of condensate through dynamicthermodynamic effects, in some regions, perturbations to microphysics are as important to surface precipitation as are perturbations to the environment; over DS, microphysical impacts can actually be larger than those of the environment (Fig. 5e). Additionally, the inclusion of environmental parameter perturbations can have an effect on the microphysical parameter sensitivities. For example, over UT in MultiParam, $\rho_{s}$ and ECI have different $\mu^{*}$ values, but when environmental parameters are simultaneously perturbed, the value for $\rho_{s}$ increases while the value for ECI decreases resulting in them having a similar influence as one another (Fig. 5c). Overall, the MP_ENV results show that RH, $\theta_{\text {sfc }}$, and $U$ are the environmental parameters causing the largest changes to PREC (Fig. 5).

Ranking all the parameters by their $\mu^{*}$ values shows the top parameters in MultiParam $\left(A_{s}, \rho_{s}\right.$, ECI, and WRA) are also relatively influential in MP_ENV, but with $A_{s}$ being the only microphysical parameter ranked as number 1 in at least one region (Fig. 6a). Relative humidity is ranked as most influential over the windward side and DT/DF regions; this may be due to its effect on the number of grid points undergoing condensation in the model, resulting in changes to spatially averaged condensation rates and the amount of condensate available to generate precipitation. Over DS, adiabatic warming leads to low RH, thus perturbations within $5 \%-10 \% \mathrm{RH}$ do not have a significant influence over this region. The surface potential temperature is most important over DT (Fig. 6a), likely due to its effect on the freezing-level height which affects the type of precipitation reaching the surface. The wind speed is most important over UF, DS, and DF (Fig. 6a), most likely due to its impact on vertical velocities associated with uplift over the elevated terrain and subsequent effects on lee-wave generation. Normalizing the $\mu^{*}$ values shows RH and $A_{s}$ are the most dominant parameters, responsible for fractional sensitivities of $30 \%-50 \%$ (Fig. $6 \mathrm{~b}$ ). The difficulty in trying to understand why $A_{s}$ is such an important microphysical parameter arises when attempting to disentangle its interactions with other parameters. However, some microphysical parameter interactions can be plausibly explained. For example, the 

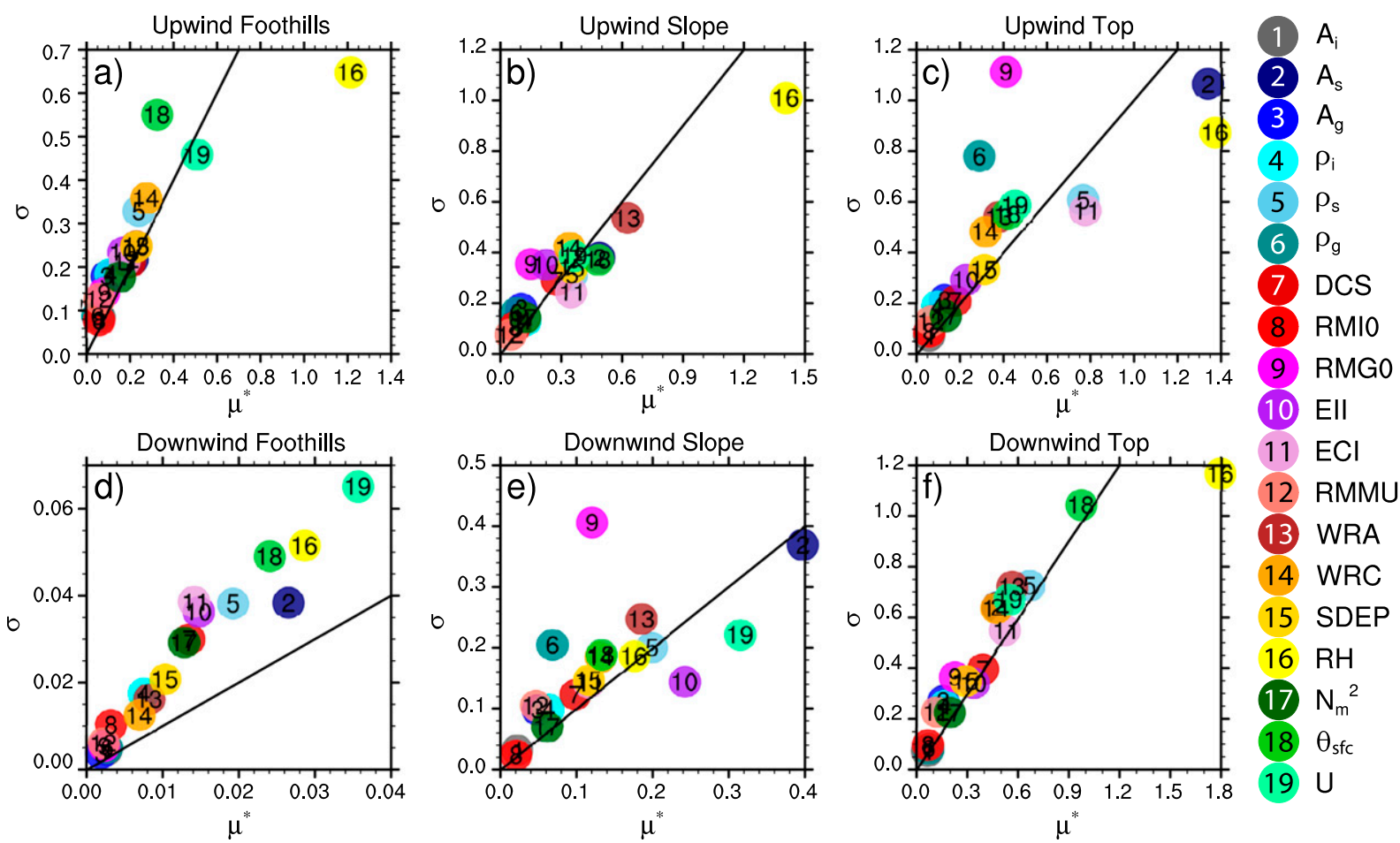

$11 \mathrm{ECl}$

12 RMMULT

(13) WRA

14 WRC

15 SDEP

$16 \mathrm{RH}$

(17) $\mathrm{N}_{\mathrm{m}}{ }^{2}$

(18) $\theta_{\mathrm{sfc}}$

$19 \mathrm{U}$

FIG. 5. As in Fig. 3, but for MP_ENV, which includes the additional four environmental parameters varied using MOAT. Labels $j=1-19$ correspond to the parameters listed in Table 1.

response of PREC to changes in ECI is moderately anticorrelated with the response to changes in $A_{s}$ (correlation coefficient $r=-0.53$ ). An increase in ECI results in more snow converted into graupel owing to more efficient riming of snow by cloud water, and because $A_{s}$ only acts on existing snow, this reduction of the snow amount aloft limits the effect of perturbations to $A_{s}$. To quantify which

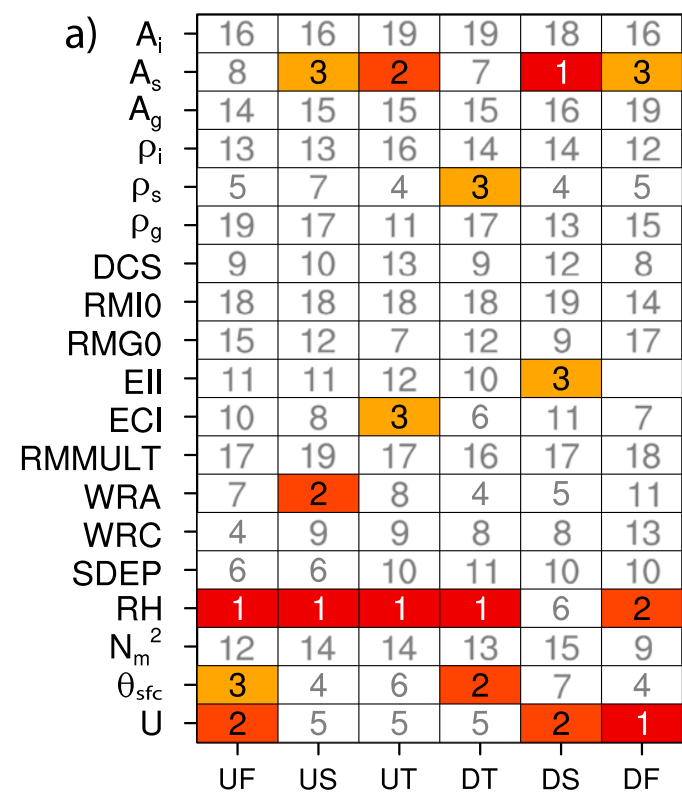

b)

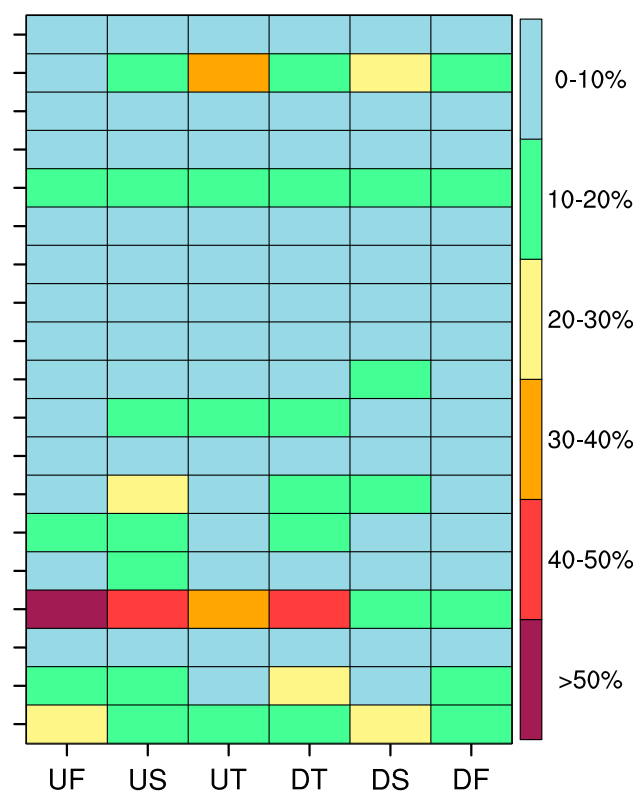

FIG. 6. As in Fig. 4, but for MP_ENV, which includes the additional four rows for the environmental parameters described in Table 1. 
TABLE 3. Ratio (\%) of maximum $\mu_{j}^{*}$ for $j=1-15$ to $\mu_{j}^{*}$ for $j=16$, 18, and 19 for experiment MP_ENV.

\begin{tabular}{lccrrrr}
\hline \hline & $\begin{array}{c}\text { UF } \\
(\text { WRC })\end{array}$ & $\begin{array}{c}\text { US } \\
(\text { WRA })\end{array}$ & $\begin{array}{r}\text { UT } \\
\left(A_{s}\right)\end{array}$ & $\begin{array}{c}\text { DT } \\
\left(\rho_{s}\right)\end{array}$ & $\begin{array}{c}\text { DS } \\
\left(A_{s}\right)\end{array}$ & $\begin{array}{r}\text { DF } \\
\left(A_{s}\right)\end{array}$ \\
\hline RH & 20 & 45 & 98 & 37 & 226 & 74 \\
$\theta$ & 85 & 130 & 320 & 68 & 298 & 110 \\
$U$ & 54 & 172 & 171 & 122 & 126 & 93 \\
\hline
\end{tabular}

parameter combinations are acting together to influence PREC, a variance-based or Bayesian method would be required (Saltelli et al. 2008), which is beyond the scope of this study.

The MP_ENV fractional sensitivity results show that over the regions with the largest $\mu^{*}$ (UF, US, UT, and DT), the upwind top is the only location where both microphysical and environmental parameter perturbations have a large effect on PREC. If we compare the change in PREC caused by the three most influential environmental parameters $\left(\mathrm{RH}, \theta_{\text {sfc }}\right.$, and $U$ ) to the maximum change in PREC caused by any microphysical parameter we observe generally similar magnitudes (Table 3). For example, over the upwind top the value of $\mu^{*}$ for $A_{s}$ (ranked 2) is $98 \%$ of the value for relative humidity (ranked 1 ). MP_ENV results show that both microphysical and environmental parameter perturbations can result in similar changes to PREC when perturbing over a typical observational uncertainty range for the environmental parameters.

Total condensation rate $\langle$ COND $\rangle$ (vertically integrated and horizontally averaged over the domain subregions) is primarily affected by changes to the dynamics (vertical motion) and relative humidity, and secondarily by changes to the temperature. Figure 7 shows the parameters most influential (highest values of $\left.\mu^{*}\right)$ to $\langle\mathrm{COND}\rangle$ are $\mathrm{RH}, U, \theta_{\mathrm{sfc}}$, and WRA. Moving downwind over the mountain, we see more microphysical parameters acting to influence $\langle\mathrm{COND}\rangle$, with the largest $\mu^{*}$ values occurring over DF and DS (Fig. 7). These results show that the environmental parameters strongly impact condensation, as expected, through changes in the dynamics and thermodynamics. For example, increased $U$ results in larger vertical velocities upwind of the mountaintop, which triggers strong downslope winds and generates lee waves. Changes to $\theta_{\text {sfc }}$ affect the height of the freezing level and directly impact cloud water condensation/evaporation through the model's saturation adjustment scheme, while perturbing $\mathrm{RH}$ can influence the number of grid points that undergo condensation and thus the average condensation rate. WRA was shown to be a key influence on $\langle\mathrm{COND}\rangle$ in M18, but using MOAT shows us that other microphysical parameters can also strongly affect condensation (Fig. 7), evidently by impacting
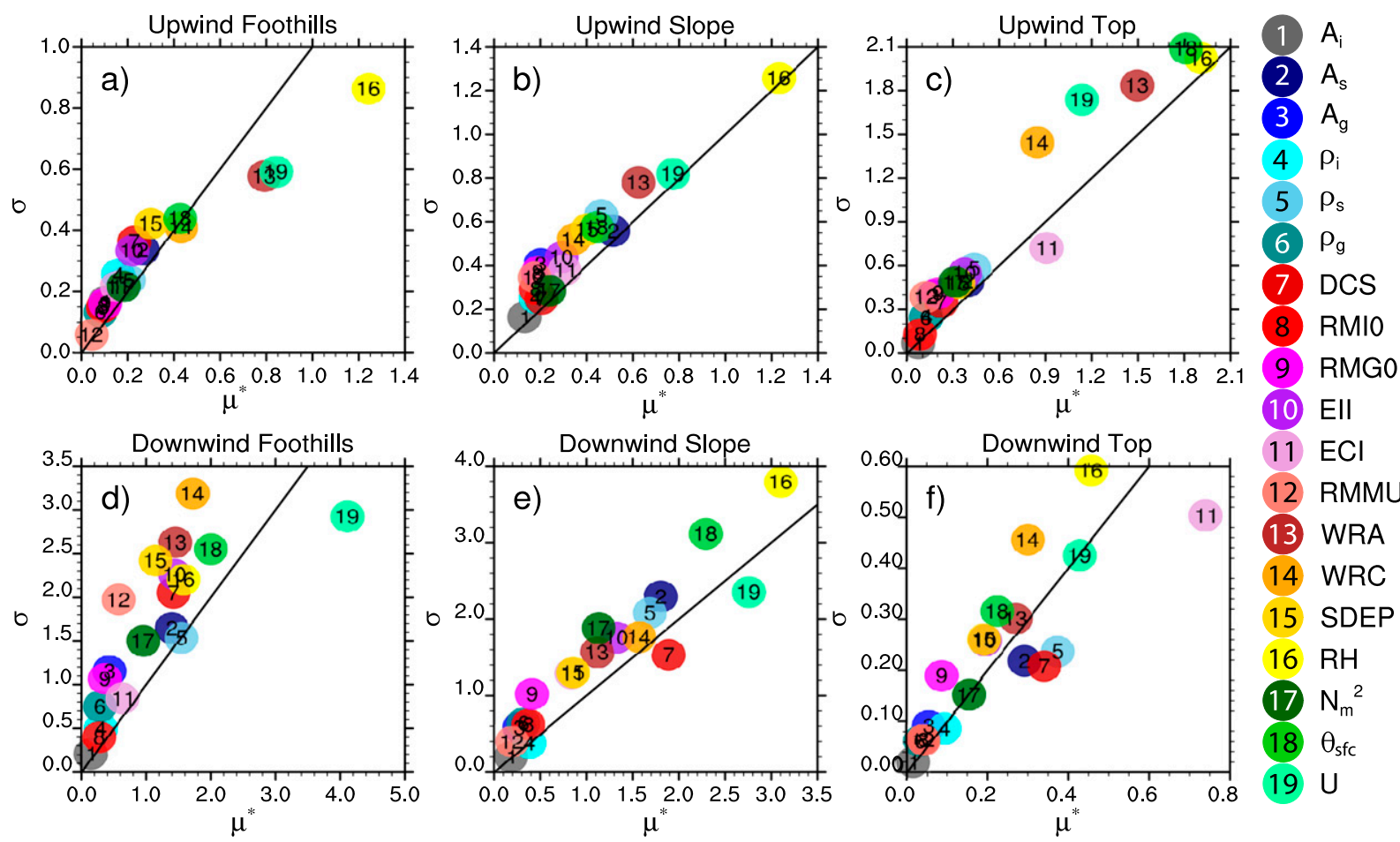

$11 \mathrm{EC}$

12 RMMULT

13 WRA

14 WRC

15 SDEP

$16 \mathrm{RH}$

$17 \mathrm{~N}_{\mathrm{m}}{ }^{2}$

$18 \theta_{\text {sfc }}$

$19 \mathrm{U}$

FIG. 7. As in Fig. 5, but for total condensation rate $\left(\mathrm{mm} \mathrm{h}^{-1}\right)$. 

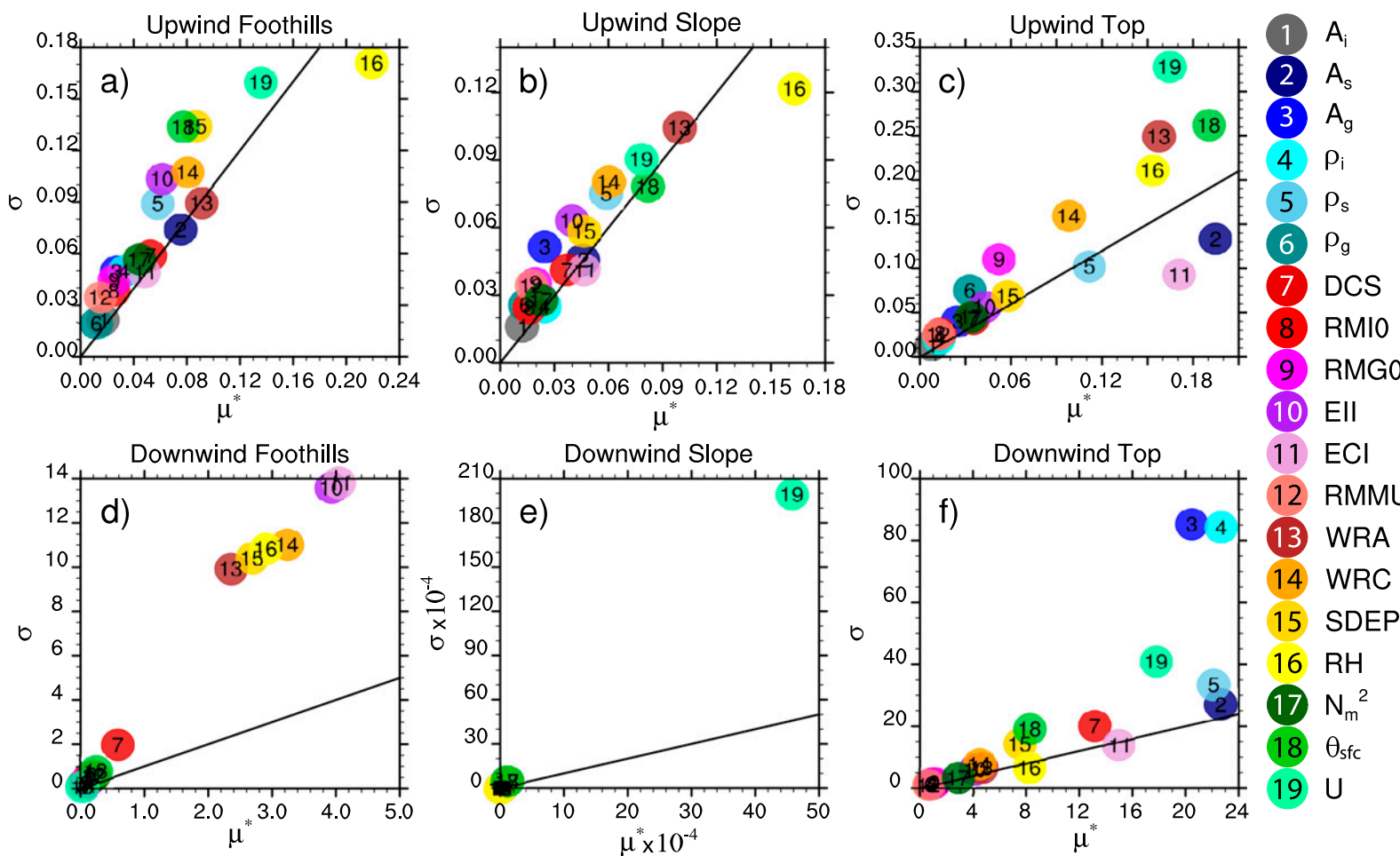

$11 \mathrm{ECl}$

12 RMMULT

FIG. 8. As in Fig. 5, but for precipitation efficiency.

lee-wave development which affects cloud development downwind of the mountain.

Because precipitation efficiency PE is affected both by microphysical processes acting on condensate and condensate transport, it is reasonable that both microphysical and environmental parameters influence it (Fig. 8). Changes to $\theta_{\text {sfc }}$ affect the phase of condensed water as well as the condensation rate, and changes to $U$ directly impact condensate horizontal transport. Values of $\mu^{*}$ for PE become very large over the downwind slope (Fig. 8) because microphysical and environmental parameter perturbations affect transport of condensate to this region by horizontal advection, which can lead to relatively large PREC despite little generation of condensate locally, and hence very large values of PE. This analysis shows that the large changes in PREC over UT from perturbations to $A_{s}$ (Fig. 5c) are seemingly a result of the large a)

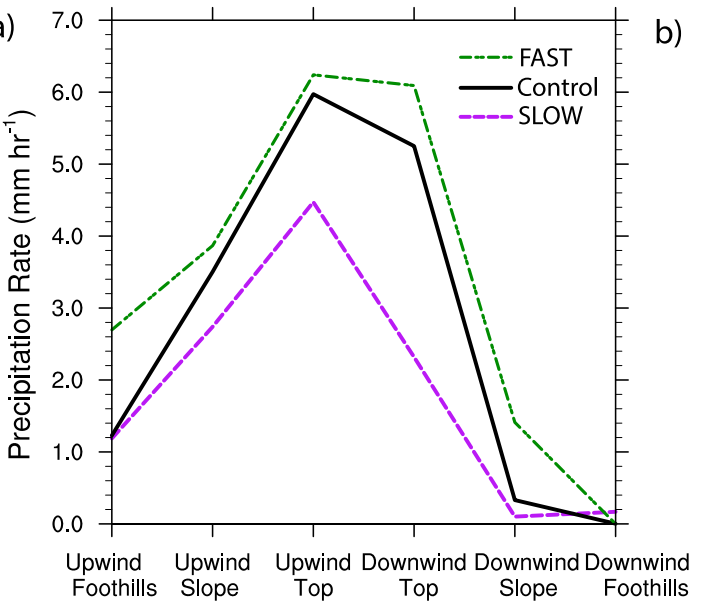

b)

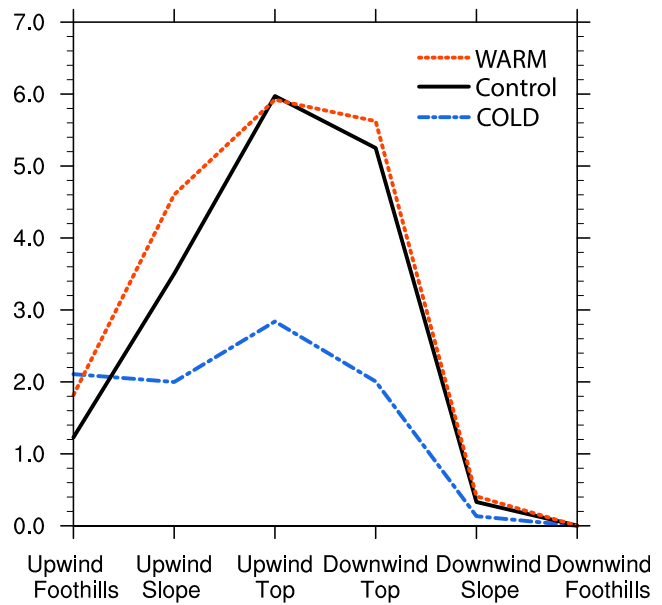

FIG. 9. Temporally (hours 6-20) and spatially averaged (six regions) precipitation rate $\left(\mathrm{mm} \mathrm{h}^{-1}\right)$ for simulations with default microphysical parameter values and (a) reduced and increased wind speeds and (b) lower and higher $\theta_{\text {sfc. }}$. Solid black lines represent values using the control sounding. 

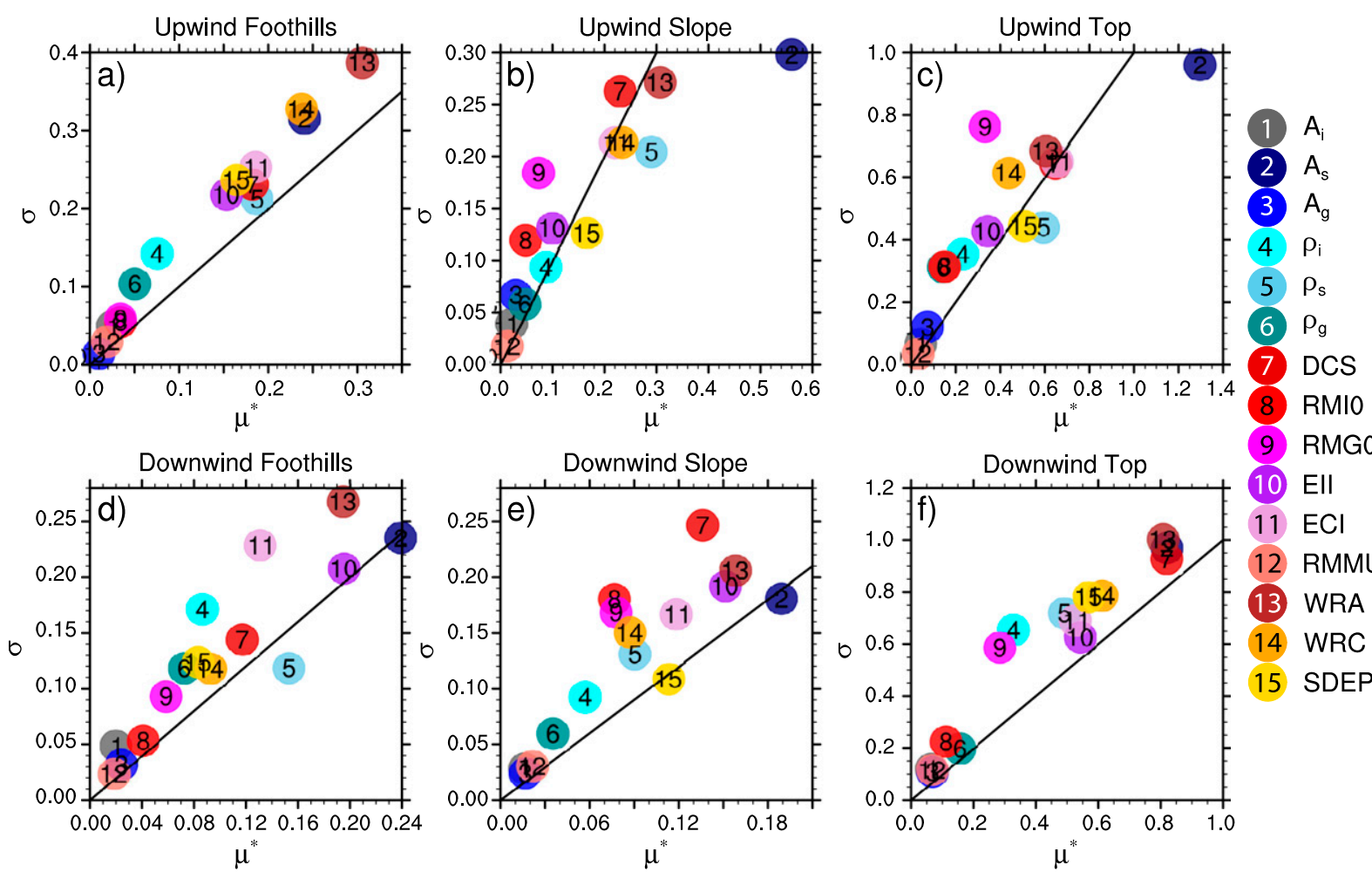

FIG. 10. As in Fig. 3, but for experiment MP_SLOW.

influence $A_{s}$ has on PE (Fig. 8c) compared to $\langle$ COND $\rangle$ (Fig. 7c). Thus, supporting the findings in M18, which conclude that the direct effects of $A_{s}$ on the snow fall speed, and hence transport, are the primary mechanism for this parameter's strong influence on PREC.

\section{c. Microphysical parameter perturbations in different environments}

The MP_ENV results showed that microphysical parameter sensitivities are affected by relatively small changes in environmental parameters, and since the range of values chosen for the parameters can influence the results, we test different wind speed and surface potential temperature regimes within a climatological range to understand the impact of different processes and changes to available precipitable water on PREC. Figure 9 shows a summary of PREC for simulations using the default microphysical parameter values and the MP_COLD, MP_WARM, MP_SLOW, and MP_FAST environments, compared to using the control environment. For the different wind regimes, the overall pattern of precipitation is similar, with a PREC peak over the upwind top (Fig. 9a) and frozen precipitation only occurring over the mountaintops (not shown). The difference in PREC values between the slower- and faster-wind-speed environments is mainly caused by changes to the vertical velocities over the upwind slope. Averaging over hours 6-20 and over the windward side, a maximum vertical velocity of $0.13 \mathrm{~m} \mathrm{~s}^{-1}$ occurs at a height of $\sim 1.5 \mathrm{~km}$ above mean sea level (MSL) in the slower-wind-speed case, while the faster-wind-speed case produces a maximum vertical velocity of $0.25 \mathrm{~m} \mathrm{~s}^{-1}$ at a height of $2.7 \mathrm{~km}$ MSL. The warm environment is more similar to the control, but with slightly more precipitation over the upwind foothills/slope (Fig. 9b). The freezing level in this case is approximately $1 \mathrm{~km}$ above the mountaintop, thus there is a significant depth where frozen hydrometeors can melt. The only region where frozen precipitation occurs in the control and warm environment is over the mountaintop. The cold environment has two PREC peaks, one over the upwind foothills where both liquid and frozen precipitation occurs and the other over the upwind top where all precipitation is frozen (Fig. 9b). In this case, the freezing level intersects the mountain at about $1 \mathrm{~km}$ MSL, so that rain is limited to the UF and US regions, while all other regions have only frozen precipitation (not shown). The large difference in PREC amounts between the warm/control environments and the cold environment is caused by a reduction in precipitable water in the cold environment; it has precipitable water of $16 \mathrm{~cm}$, while the warm and 

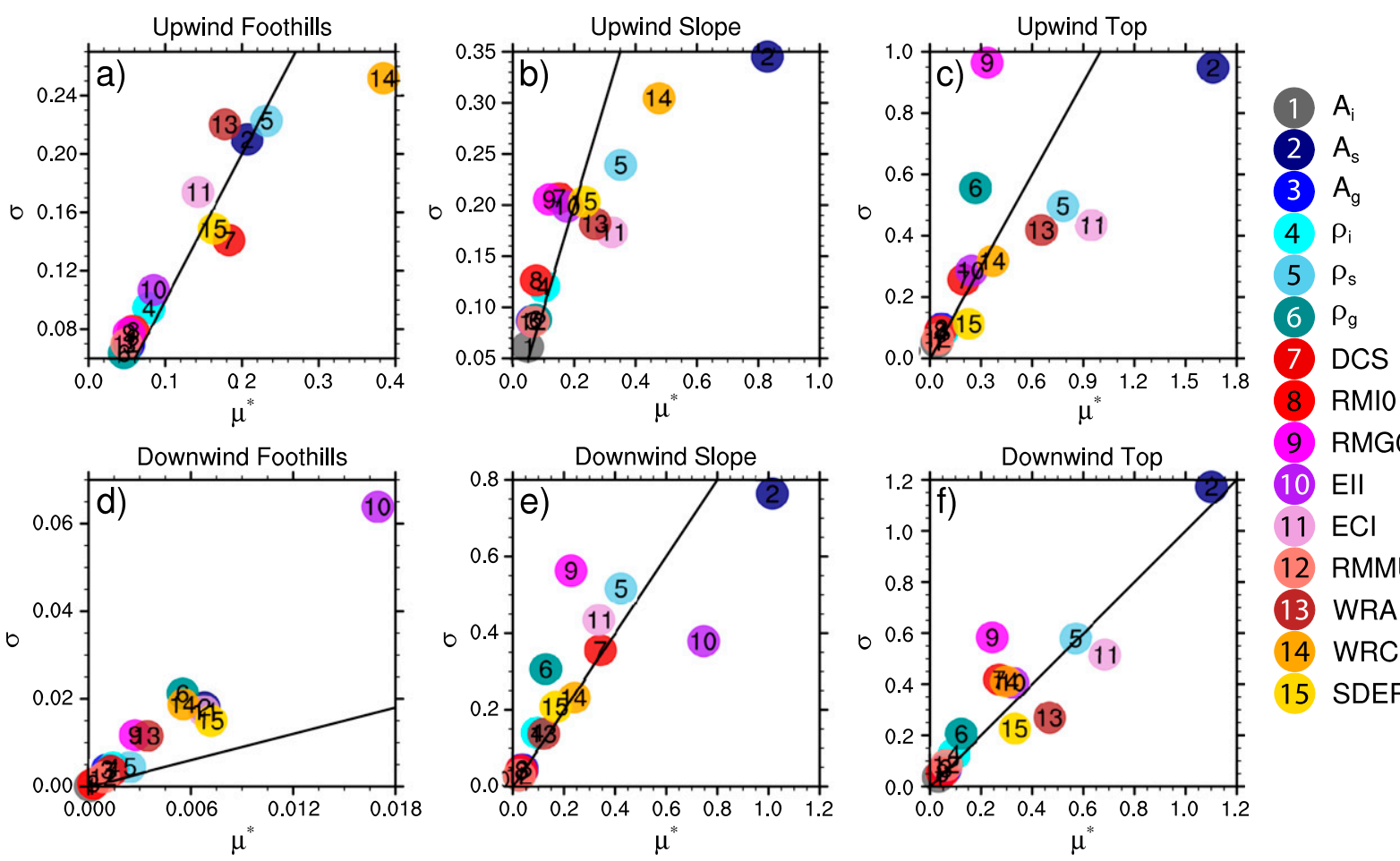

9) RMG0

10 EII

$11 \mathrm{ECl}$

12 RMMULT

13 WRA

14 WRC

15 SDEP

FIG. 11. As in Fig. 3, but for experiment MP_FAST.

control environments have values of 33 and $27 \mathrm{~cm}$, respectively.

\section{1) MOAT RESULTS FOR WIND SPEED REGIMES}

Results for MP_SLOW show that perturbations to the microphysical parameters produce the largest influence on PREC over US, UT, and DT. The most influential parameter over US and UT is $A_{s}$ (Fig. 10), similar to the control environment. Over DT, the largest $\mu^{*}$ values are caused by WRA, DCS, and $\rho_{s}$. The MP_FAST results have the largest $\mu^{*}$ values over both slopes and tops and $A_{s}$ is the most influential parameter in all four locations (Fig. 11). Microphysical parameters that are moderately influential in this case are WRC, ECI, EII, WRA, and $\rho_{s}$.

Fractional sensitivity results for these two experiments show there are many more microphysical parameters with FS $>20 \%$ in MP_SLOW (Fig. 12a) than in MP_FAST (Fig. 12b) or the control (Fig. 4b). We surmise that the weaker sensitivity to microphysics in MP_FAST and the control may be due to those environments being more dynamically forced. Stated another way, more rapid flow leads to stronger water vapor flux convergence upwind, and as such, condensate will form and precipitate regardless of changes to microphysical parameter values. Differences in fractional sensitivity over the downwind regions between MP_SLOW and MP_FAST may be due to the different mountain-wave regimes that develop given the change in wind speed. The environment in MP_SLOW produces vertically propagating, largeamplitude lee waves, while MP_FAST and the control simulation produce trapped lee waves with smaller amplitudes that dissipate in the vertical (Fig. 13). We hypothesize that the waves in MP_SLOW trigger a wider region downwind to reach its lifting condensation level where latent heating then further enhances buoyancy and condensate development, for example, the vertical velocities are strong enough to form graupel at midlevels (Fig. 13). MP_FAST does not form condensate downwind as the wave amplitude is small over very narrow regions. Therefore, precipitation downwind would be more sensitive to changes in microphysical parameters for MP_SLOW because this environment allows for cloud, snow, and graupel to form downwind, while condensate over DT and DS in MP_FAST is mainly formed upwind of the mountaintop and advected downwind. The control simulation does form clouds and some snow in the midlevels over DF despite the trapped lee waves; this may be due to some threshold wave amplitude being met that allows for enough upward motion to generate condensate. Nonetheless, $A_{s}$ continues to have a large fractional sensitivity regardless of wind speed regime (Figs. 12a,b). If we separate the PREC results into 


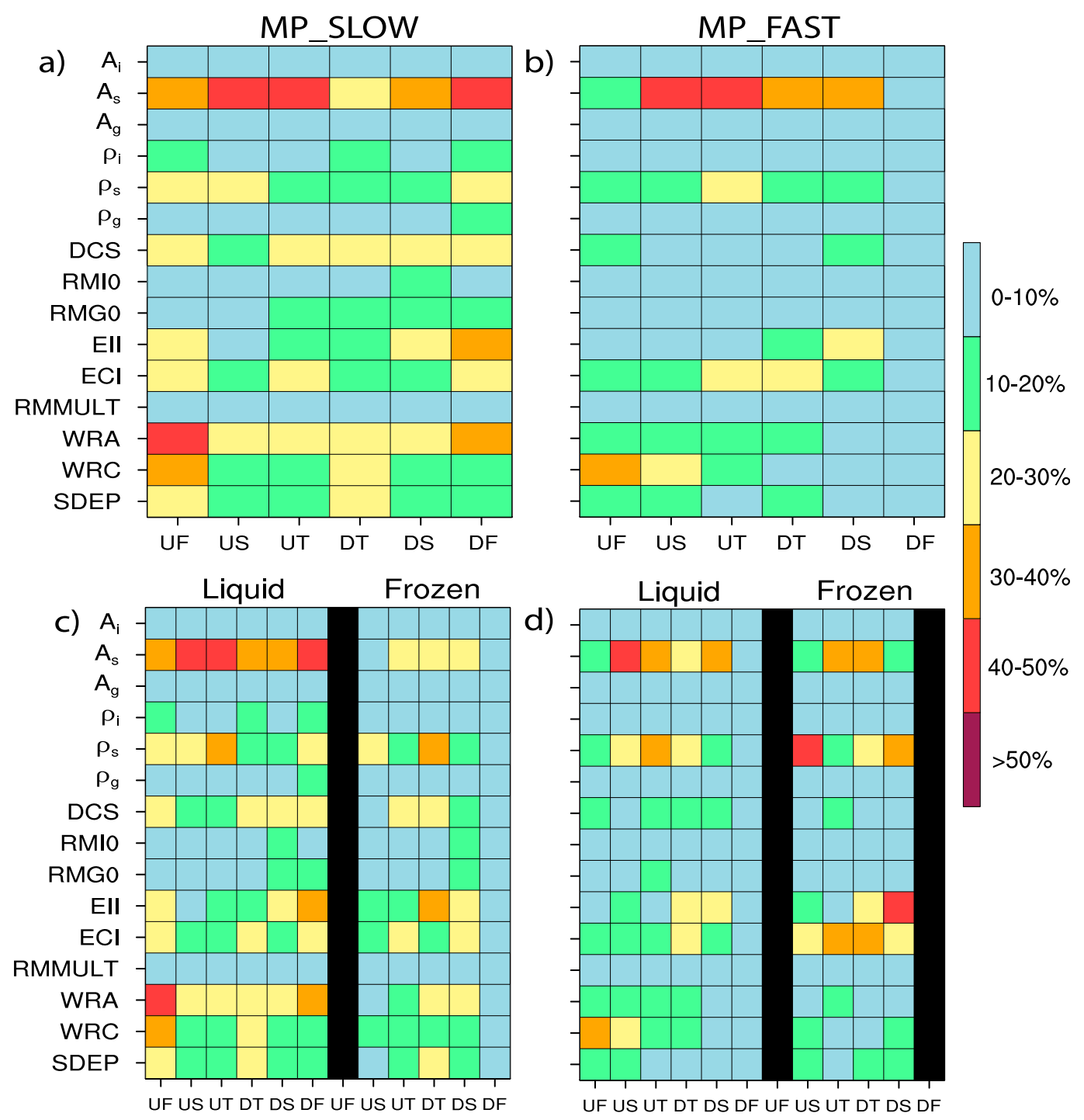

FIG. 12. (top) As in Fig. 4a, but for experiments (a) MP_SLOW and (b) MP_FAST. (bottom) Fractional sensitivity $(\%)$ for liquid and frozen precipitation rate $\left(\mathrm{mm} \mathrm{h}^{-1}\right)$ for (c) MP_SLOW and (d) MP_FAST. Black-shaded cells represent no precipitation in these regions.

liquid and frozen (snow + graupel) components, details emerge as to how each environment affects precipitation type. Results for MP_SLOW show that the liquid precipitation is most sensitive to $A_{s}$ and WRA (Fig. 12c). In MP_FAST we see that frozen precipitation is sensitive to additional parameters: $\rho_{s}$, EII, and ECI also have large impacts on frozen precipitation (Fig. 12d).

\section{2) MOAT RESULTS FOR TEMPERATURE REGIMES}

Results for MP_COLD have relatively smaller values of $\mu^{*}$ compared to the other experiments, but all regions except DF have nonnegligible values (Fig. 14). The most influential parameter for UF and DS is $A_{s}$, and for US it is WRA. The upwind and downwind tops both have a cluster of parameters considered influential in this case: $A_{s}$, WRA, EII, ECI, and WRC for UT, and $A_{s}$ and EII for DT (Figs. 14c,f). Similar to MP_FAST, results for MP_WARM show the largest $\mu^{*}$ values occur over both the mountain slopes and mountaintops (Fig. 15). In this case it is clear that $A_{s}$ is the most influential parameter overall, and WRA, WRC, ECI, and $\rho_{s}$ are moderately influential over the slopes and tops (Fig. 15).

Fractional sensitivities for PREC show that $A_{s}$ leads to FS $>30 \%$ regardless of the temperature regime. MP_COLD has more parameters with FS $>20 \%$ compared to MP_WARM; these include ice-ice 

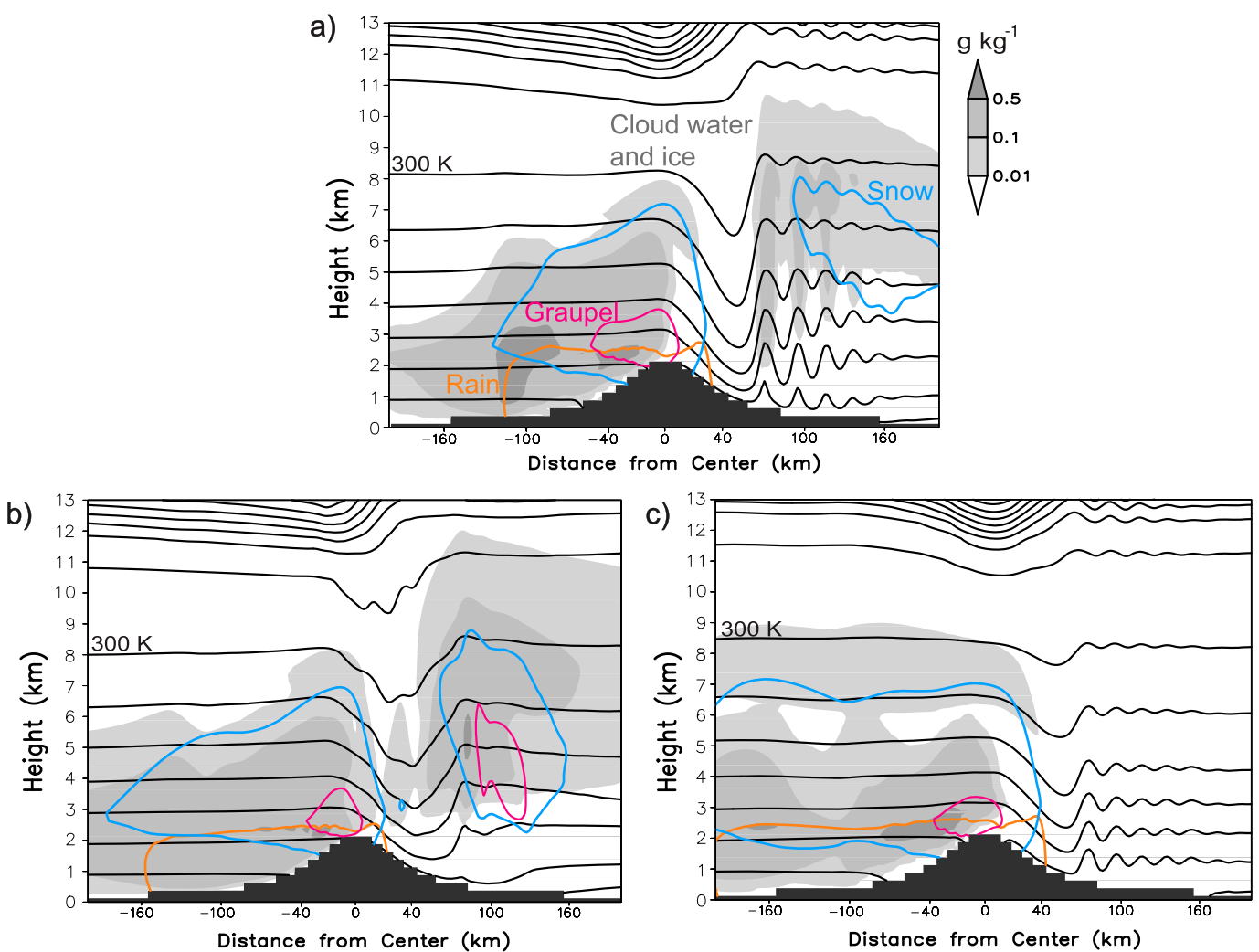

FIG. 13. Temporally averaged (hours 6-20) vertical cross sections over a portion of the domain for simulations using the (a) control sounding, (b) slower-wind-speed profile used in MP_SLOW, and (c) faster-wind-speed profile used in MP_FAST. Gray shading represents cloud water and ice mixing ratios $\left(\mathrm{g} \mathrm{kg}^{-1}\right)$. Colored contours represent the $0.05 \mathrm{~g} \mathrm{~kg}^{-1}$ mixing ratio for snow (cyan), rain (orange), and graupel (magenta). Black contours are isentropes starting at $270 \mathrm{~K}$ in $5-\mathrm{K}$ intervals, with the $300-\mathrm{K}$ isentrope is labeled for reference.

(EII) and ice-cloud water (ECI) collection efficiency, rain accretion (WRA), cloud water autoconversion (WRC), and snow deposition (SDEP) (Figs. 16a,b). Liquid precipitation is sensitive to $A_{s}$ and $\rho_{s}$ in both temperature regimes, meaning that most of the liquid precipitation may be a result of snow melting compared to warm-rain processes (Figs. 16c,d). For frozen precipitation, MP_COLD has fractional sensitivities $>30 \%$ for $A_{s}$, EII, and WRA, while $\rho_{s}$ and ECI are responsible for FS $>30 \%$ in MP_WARM (Figs. 16c,d), emphasizing the influence of mixedphase processes in a warmer environment.

\section{d. Microphysical parameterization tests}

In this section, we compare variations in PREC caused by microphysical parameter perturbations within a single scheme using MOAT (MultiParam) to those resulting from an ensemble of four different schemes (MultiPhys). The standard deviations shown in Fig. 17 for the single scheme test are calculated from the PREC values produced by all 320 simulations using MOAT, while the standard deviations for the MultiPhys experiments are calculated from the PREC values from the four-member ensemble with different schemes; all of which are calculated for the five environments: control, colder temperature, warmer temperature, slower wind speed, and faster wind speed. Results from these tests show standard deviations for parameter perturbations in a single scheme produce variations in PREC with a similar order of magnitude to those caused by choosing an entirely different scheme (Fig. 17). We also see a strong spatial nonlinearity of precipitation sensitivities, that is, standard deviations vary with location over the mountain. For the MultiPhys experiments, the standard deviations are largest over DT for warm, fast, and slow environments, while the peak standard deviations occur over UT for the control and cold environments (Fig. 17).

\section{Summary and conclusions}

CM1 was used to perform idealized 2D simulations of moist, nearly neutral flow over a bell-shaped mountain. The model configurations and initial sounding were similar to that used in M18, except a 2-km mountain 

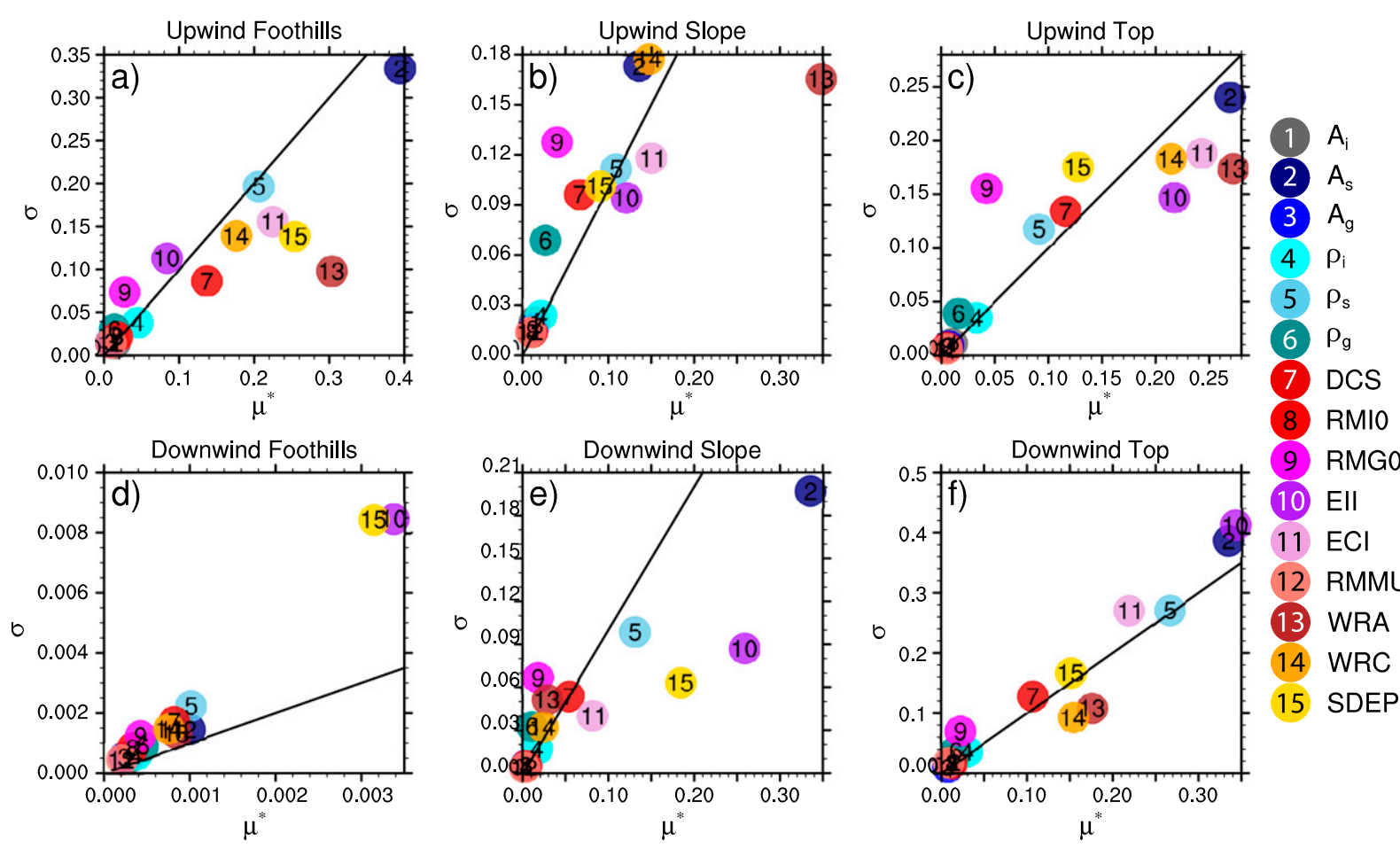

9) RMGO

10 EII

$11 \mathrm{ECl}$

12 RMMULT

13 WRA

14 WRC

15 SDEP

FIG. 14. As in Fig. 3, but for experiment MP_COLD.

height is used here. Experiments perturbing multiple microphysical parameters (MultiParam) were compared to experiments where both microphysical and environmental parameters were simultaneously perturbed (MP_ENV). The objective of these simulations was to explore orographic precipitation sensitivities to microphysical and environmental parameter perturbations using the Morris one-at-a-time (MOAT) method, which simultaneously perturbs a large number of parameters at low computational cost. This is in contrast to nearly all previous parameter sensitivity studies that varied parameters individually while holding all other parameter values fixed. Four different environments were also tested to determine how the multiparameter MOAT results change in colder (MP_COLD), warmer (MP_WARM), slower-wind-speed (MP_SLOW), and faster-wind-speed (MP_FAST) environments. MOAT was applied for the first time to the study of orographic precipitation sensitivity, providing unique insight on the most influential parameters to precipitation and their interaction with other parameters. Finally, we compared the PREC variability caused by perturbations to microphysical parameters within the Morrison scheme to the variability found in a four-member ensemble using entirely different microphysics schemes (MultiPhys).

The most influential parameters on orographic precipitation were $A_{s}, \rho_{s}, \mathrm{ECI}$, and WRA, especially over the upwind slope and top. These are the same parameters having the largest influence on PREC in the one-ata-time parameter perturbations tests in M18. In addition to causing a large change in PREC, $A_{s}$ had a large range of elementary effects, which demonstrated its strong interaction with other parameters. Furthermore, $A_{s}$ had a larger effect on precipitation efficiency compared to total condensation rate, emphasizing its direct effects on snow fall speed and subsequent condensate advection. The location over which each parameter is influential depended on the processes active in that region. For example, WRA was most influential over the upwind foothills and slope as these locations contained large amounts of supercooled water and a deep melting layer. Parameters $A_{s}$ and WRA were found to contribute $30 \%-50 \%$ of the total PREC variation in the MultiParam simulations.

M18 showed that large changes in the environment influence the total amount of condensate produced, thereby affecting the influence a particular microphysics parameter can have on PREC. Our focus was on understanding relative sources of model uncertainty, and as such, the environmental parameter perturbations tested were small (informed by estimates of typical observational uncertainty). Even so, these perturbations were influential to $\langle\mathrm{COND}\rangle$ and resulted in a relative decrease of microphysical parameters' influence on PREC. The most influential environmental 

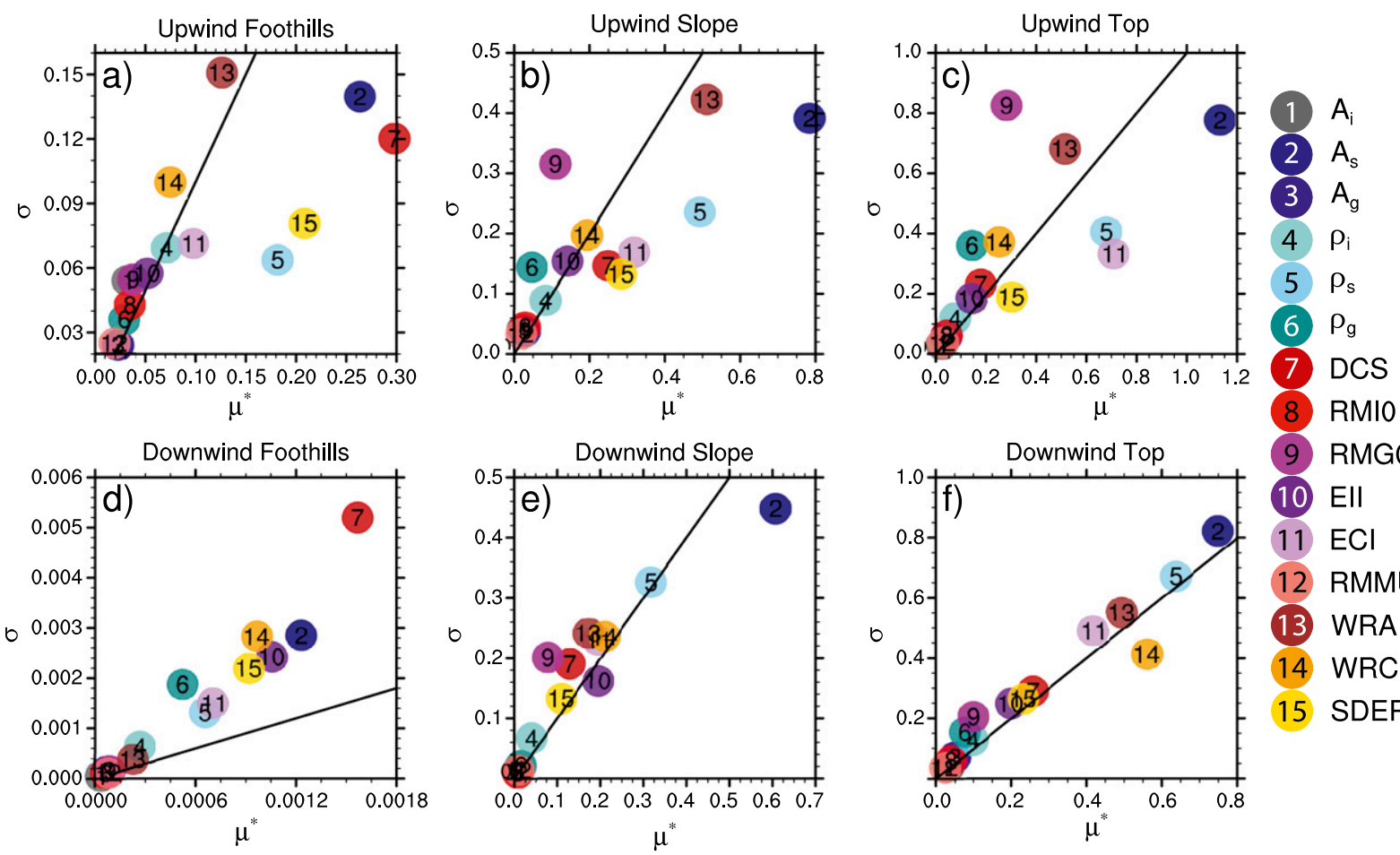

(9) RMG0

10 EII

$11 \mathrm{ECl}$

12 RMMULT

13 WRA

14 WRC

15 SDEP

FIG. 15. As in Fig. 3, but for experiment MP_WARM.

parameters to PREC were RH, $\theta_{\text {sfc }}$, and $U$, resulting in large PREC changes over the upwind foothills and slope, and downwind top, mainly due to effects on $\langle$ COND $\rangle$ through updraft development and lee-wave formation. Interestingly, out of the four most influential parameters found in MultiParam, $A_{s}$ and WRA remained influential to PREC in MP_ENV, with $A_{s}$ perturbations leading to nearly the same ( $98 \%$ as large) PREC variability over the upwind top as that caused by RH perturbations. This suggests that improved representation and observational constraint of the fall speed of snow particles would be useful. Results from this study show strong spatial variability in the parameters' influence, as well as demonstrating that both microphysical and environmental parameters are important to orographic precipitation uncertainty.

Different temperature and wind speed regimes were tested, and although these other environments impacted the amount of available condensate and location of peak precipitation, $A_{s}$ remained the most important microphysical parameter in all four environmental experiments. In the wind speed regime tests, more microphysical parameters had a fractional sensitivity $>20 \%$ in MP_SLOW compared to MP_FAST, which may be due to stronger dynamical forcing and different mountain-wave regime in the latter. The temperature regime tests showed large changes to the location and amount of liquid versus frozen precipitation. This is because the freezing level decreased in MP_COLD, leading to liquid precipitation falling mainly over the upwind slope. The spatial change in dominant precipitation processes resulted in the microphysical parameters' influence on PREC to also vary spatially. MP_WARM results showed that snow aloft was important for liquid precipitation production, while mixedphase processes were important for frozen precipitation.

This study tested many of the user-prescribed parameters within the Morrison scheme, but there remain various thresholds and processes within the scheme that could be tested with MOAT in the future. A caveat of the MOAT method is that results may change depending on the range of uncertainty used. Parameter sensitivities would need to be retested if a specific parameter's uncertainty range were to be narrowed, but results would be dependent on whether that parameter interacts with the others, that is, if that parameter has no influence on other parameters, then changing its uncertainty range will not cause much change in the results.

The MultiPhys experiment showed that variation in PREC caused by perturbations to microphysical parameters within the Morrison scheme was similar in magnitude to the variation found in a four-member ensemble using different microphysics schemes. A common method to account for uncertainty in the 

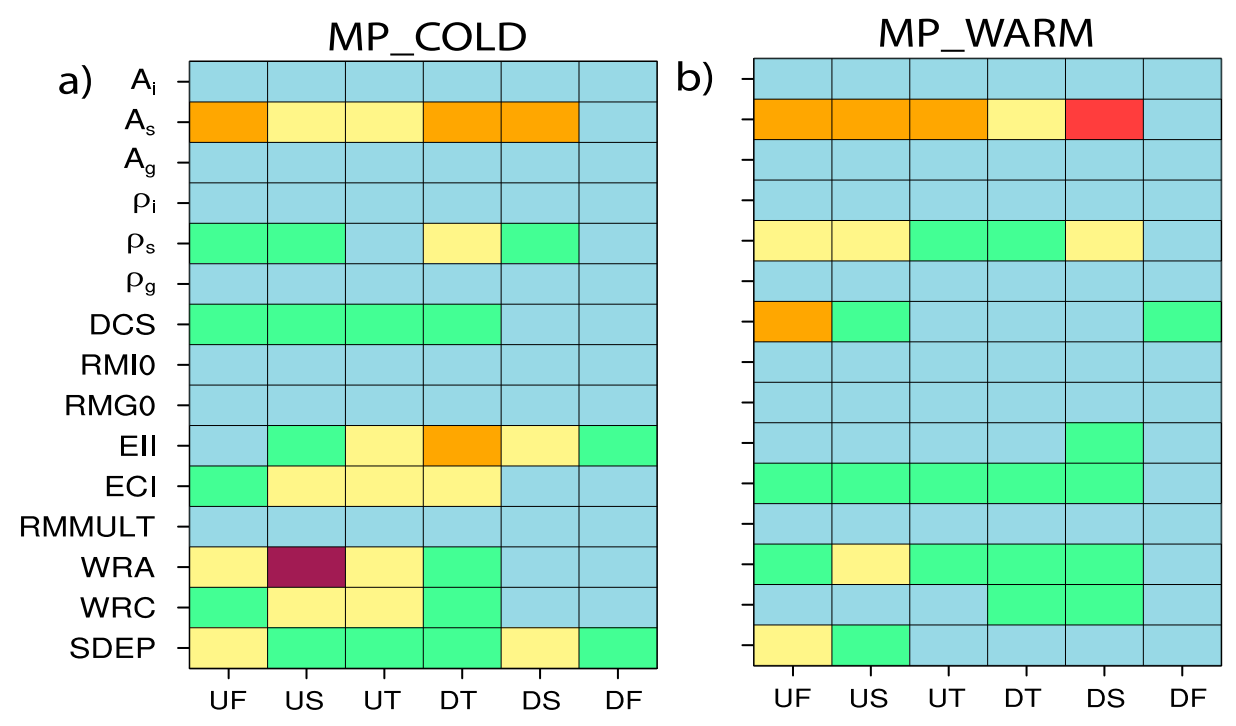

MP_WARM
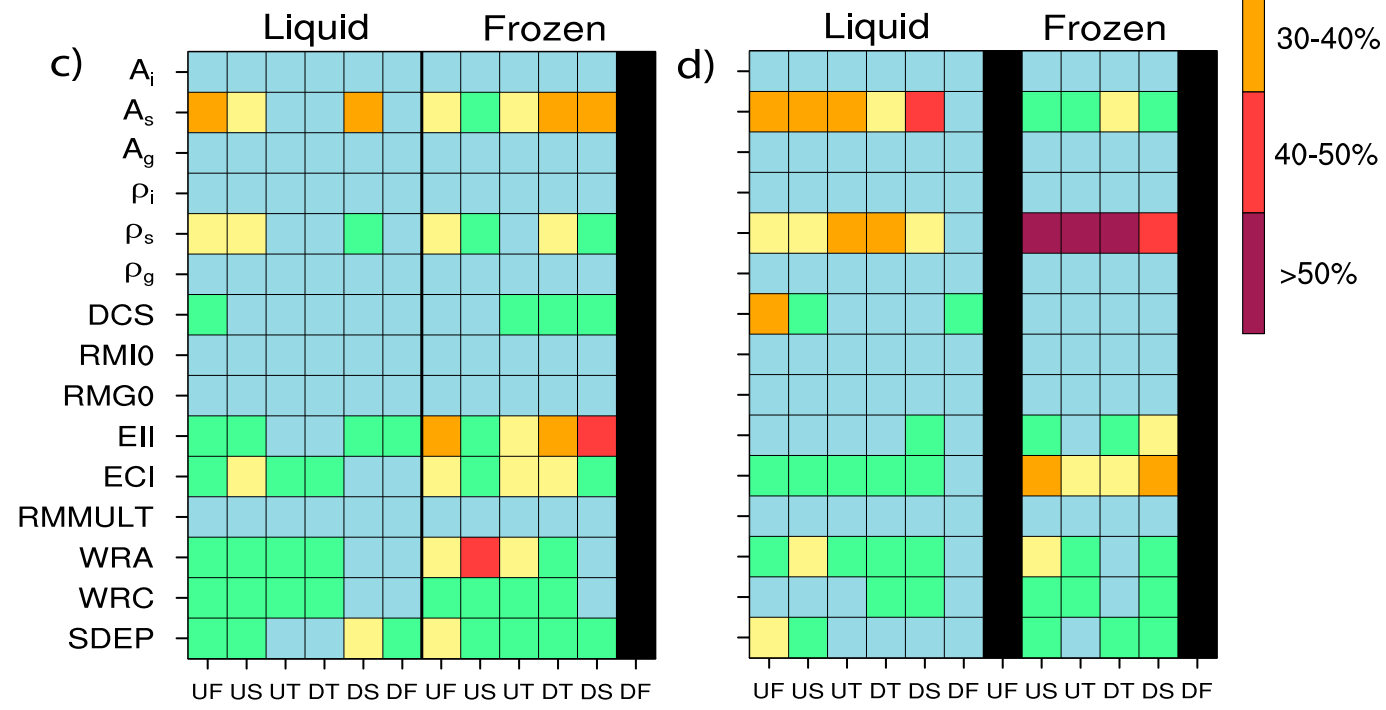

FIG. 16. As in Fig. 12, but for experiments (a),(c) MP_COLD and (b),(d) MP_WARM.

representation of microphysics in numerical weather prediction is to create ensembles where each member uses a different combination of physics schemes, including microphysics (e.g., Eckel and Mass 2005; Xue et al. 2009; Schwartz et al. 2010; Clark et al. 2011; Johnson and Wang 2012, 2013). The results presented herein hint that similar variability can be achieved by varying parameters within a single scheme for orographic precipitation cases, particularly when the choice of most influential parameters to vary is informed by statistical analysis as in our study using the MOAT method. Multiparameter ensembles are potentially advantageous because physical interpretation of differences among ensemble members is straightforward, unlike for multiphysics scheme ensembles in which numerous processes and parameters are represented differently among schemes. Stochastic parameterizations can add an additional level of realism to an ensemble by varying parameters spatially and temporally. Recent studies show these ensemble approaches can result in increased ensemble spread (Jankov et al. 2017, 2019), but more research needs to be done before these methods are applied operationally. We recommend future studies explore the application of stochastic parameterization to microphysical processes for orographic precipitation.

Studies have shown a systematic overprediction of orographic precipitation during cold wintertime storms, that is, storms whose freezing level exists below the average mountain height (Lin et al. 2013). This positive model bias is thought to be related to the representation of ice processes within bulk microphysics schemes and 

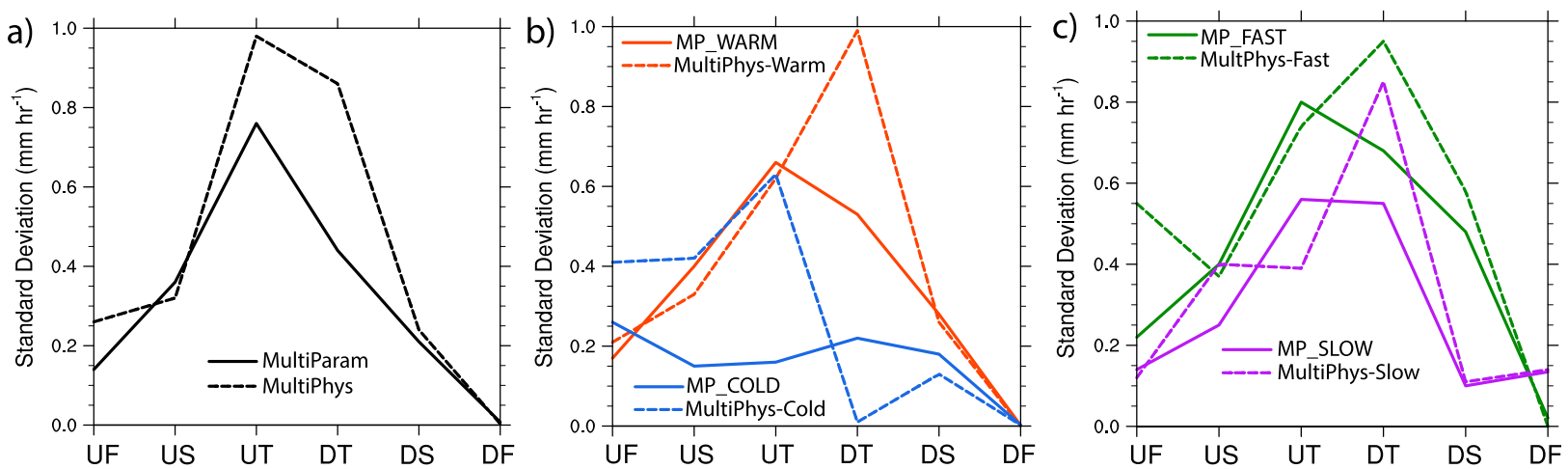

FIG. 17. Precipitation-rate standard deviation $\left(\mathrm{mm} \mathrm{h}^{-1}\right)$ temporally averaged (hours 6-20) and spatially averaged (six regions) for the (a) control environment (black), (b) warmer (orange) and colder (blue) environments, and (c) slower- (purple) and faster- (green) windspeed environments. Solid lines represent results from multiple microphysical parameter perturbations using a single scheme with MOAT. Dashed lines represent the MultiPhys experiment. See Table 2 for a description of the simulations.

thermodynamic/dynamic processes that can affect these processes (Lin et al. 2013). Thus, including microphysical parameters in ensemble forecasting through stochastic parameterization may lead to an improvement in these model biases. More testing using threedimensional forecast models for real orographic precipitation case studies is needed to further explore this idea. Future work will build on our MOAT results using a Bayesian framework to explore the parameter space and posterior parameter distributions in the context of an observational "truth."

Acknowledgments. The authors would like to acknowledge George Bryan for his help with the CM1 source code and Ethan Gutmann for his helpful suggestions. A.M. is hosted by the National Center for Atmospheric Research (NCAR) and the Mesoscale and Microscale Meteorology Lab. Part of this work was funded by NASA Interdisciplinary Science Grant NNX14AG68G and the University of Michigan's Rackham Predoctoral Fellowship. H.M. was partially supported by the U.S. Department of Energy Atmospheric System Research Grant DE-SC0016476. NCAR is sponsored by the National Science Foundation. A portion of this research was carried out at the Jet Propulsion Laboratory, California Institute of Technology, under a contract with the National Aeronautics and Space Administration.

\section{REFERENCES}

Bryan, G. H., and J. M. Fritsch, 2002: A benchmark simulation for moist nonhydrostatic numerical models. Mon. Wea. Rev., 130, 2917-2928, https://doi.org/10.1175/1520-0493(2002)130<2917: ABSFMN $>2.0 . \mathrm{CO} ; 2$.

Campolongo, F., J. Cariboni, and A. Saltelli, 2007: An effective screening design for sensitivity analysis of large models.
Environ. Modell. Software, 22,1509-1518, https://doi.org/10.1016/ j.envsoft.2006.10.004.

Castellano, N. E., E. E. Avila, and C. P. R. Saunders, 2004: Theoretical model of the Bergeron-Findeisen mechanism of ice crystal growth in clouds. Atmos. Environ., 38, 6751-6761, https://doi.org/10.1016/j.atmosenv.2004.09.003.

Clark, A. J., and Coauthors, 2011: Probabilistic precipitation forecast skill as a function of ensemble size and spatial scale in a convection-allowing ensemble. Mon. Wea. Rev., 139, 1410-1418, https://doi.org/10.1175/2010MWR3624.1.

Colle, B. A., 2004: Sensitivity of orographic precipitation to changing ambient conditions and terrain geometries: An idealized modeling perspective. J. Atmos. Sci., 61, 588-606, https://doi.org/ 10.1175/1520-0469(2004)061<0588:SOOPTC > 2.0.CO;2.

, and C. F. Mass, 2000: The 5-9 February 1996 flooding event over the Pacific Northwest: Sensitivity studies and evaluation of the MM5 precipitation forecasts. Mon. Wea. Rev., 128, 593-617, https://doi.org/10.1175/1520-0493(2000)128<0593: TFFEOT $>2.0 . \mathrm{CO} ; 2$.

, and Y. Zeng, 2004a: Bulk microphysical sensitivities within the MM5 for orographic precipitation. Part I: The Sierra 1986 event. Mon. Wea. Rev., 132, 2780-2801, https://doi.org/ 10.1175/MWR2821.1.

, and - 2004b: Bulk microphysical sensitivities within the MM5 for orographic precipitation. Part II: Impact of barrier width and freezing level. Mon. Wea. Rev., 132, 2802-2815, https://doi.org/10.1175/MWR2822.1.

, M. F. Garvert, J. B. Wolfe, C. F. Mass, and C. P. Woods, 2005: The 13-14 December 2001 IMPROVE-2 event. Part III: Simulated microphysical budgets and sensitivity studies. J. Atmos. Sci., 62, 3535-3558, https://doi.org/10.1175/ JAS3552.1.

Covey, C., D. D. Lucas, J. Tannahill, and X. Garaizar, 2013: Efficient screening of climate model sensitivity to a large number of perturbed input parameters. J. Adv. Model. Earth Syst., 5, 598-610, https://doi.org/10.1002/jame.20040.

Dettinger, M. D., F. M. Ralph, T. Das, P. J. Neiman, and D. R. Cayan, 2011: Atmospheric rivers, floods and the water resources of California. Water, 3, 445-478, https://doi.org/10.3390/w3020445.

Doyle, J. D., and Coauthors, 2000: An intercomparison of modelpredicted wave breaking for the 11 January 1972 Boulder windstorm. Mon. Wea. Rev., 128, 901-914, https://doi.org/ 10.1175/1520-0493(2000)128<0901:AIOMPW>2.0.CO;2. 
Durran, D. R., 1990: Atmospheric Processes over Complex Terrain. Meteor. Monogr., No. 45, Amer. Meteor. Soc., 394 pp. , and J. B. Klemp, 1982: On the effects of moisture on the Brunt-Väisälä frequency. J. Atmos. Sci., 39, 2152-2158, https://doi.org/10.1175/1520-0469(1982)039<2152:OTEOMO> 2.0.CO;2.

Eckel, F. A., and C. F. Mass, 2005: Aspects of effective mesoscale, short-range ensemble forecasting. Wea. Forecasting, 20, 328350, https://doi.org/10.1175/WAF843.1.

Gilmore, M. S., J. M. Straka, and E. N. Rasmussen, 2004: Precipitation uncertainty due to variations in precipitation particle parameters within a simple microphysics scheme. Mon. Wea. Rev., 132, 2610-2627, https://doi.org/10.1175/ MWR2810.1.

Hobbs, P. V., R. C. Easter, and A. B. Fraser, 1973: A theoretical study of the flow of air and fallout of solid precipitation over mountainous terrain: Part II: Microphysics. J. Atmos. Sci., 30, 813-823, https://doi.org/10.1175/1520-0469(1973) $030<0813$ :ATSOTF $>2.0$. CO 2 .

Houze, R. A., Jr., and Coauthors, 2017: The Olympic Mountains Experiment (OLYMPEX). Bull. Amer. Meteor. Soc., 98, 2167-2188, https://doi.org/10.1175/BAMS-D-16-0182.1.

Jankov, I., P. J. Schultz, C. J. Anderson, and S. E. Koch, 2007: The impact of different physical parameterizations and their interactions on cold season QPF in the American River Basin. J. Hydrometeor., 8, 1141-1151, https://doi.org/ 10.1175/JHM630.1.

, J.-W. Bao, P. J. Neiman, P. J. Schultz, H. Yuan, and A. B. White, 2009: Evaluation and comparison of microphysical algorithms in ARW-WRF model simulations of atmospheric river events affecting the California coast. J. Hydrometeor., 10, 847-870, https://doi.org/10.1175/ 2009JHM1059.1.

—_, and Coauthors, 2017: A performance comparison between multiphysics and stochastic approaches within a North American RAP ensemble. Mon. Wea. Rev., 145, 1161-1179, https://doi.org/10.1175/MWR-D-16-0160.1.

— J. Beck, J. Wolff, M. Harrold, J. B. Olson, T. Smirnova, C. Alexander, and J. Berner, 2019: Stochastically perturbed parameterizations in an HRRR-based ensemble. Mon. Wea. Rev., 147, 153-173, https://doi.org/10.1175/MWR-D18-0092.1.

Johnson, A., and X. Wang, 2012: Verification and calibration of neighborhood and object-based probabilistic precipitation forecasts from a multi-model convection-allowing ensemble. Mon. Wea. Rev., 140, 3054-3077, https://doi.org/10.1175/ MWR-D-11-00356.1.

- and 2013: Object-based evaluation of a storm scale ensemble during the 2009 NOAA Hazardous Weather Testbed Spring Experiment. Mon. Wea. Rev., 141, 1079-1098, https://doi.org/10.1175/MWR-D-12-00140.1.

King, D. M., and B. J. C. Perera, 2013: Morris method of sensitivity analysis applied to assess the importance of input variables on urban water supply yield-A case study. J. Hydrol., 477, 1732, https://doi.org/10.1016/j.jhydrol.2012.10.017.

Kirshbaum, D., and R. B. Smith, 2008: Temperature and moiststability effects on midlatitude orographic precipitation. Quart. J. Roy. Meteor. Soc., 134, 1183-1199, https://doi.org/ 10.1002/qj.274.

Kunz, M., and C. Kottmeier, 2006: Orographic enhancement of precipitation over low mountain ranges. Part I: Model formulation and idealized simulations. J. Appl. Meteor. Climatol., 45, 1025-1040, https://doi.org/10.1175/JAM2389.1.
_ , and S. Wassermann, 2011: Moist dynamics and orographic precipitation related to ambient conditions. Meteor. Z., 20, 199-215, https://doi.org/10.1127/0941-2948/2011/0221.

Lin, Y., and B. A. Colle, 2009: The 4-5 December 2001 IMPROVE-2 event: Observed microphysics and comparisons with the Weather Research and Forecasting Model. Mon. Wea. Rev., 137, 1372-1392, https://doi.org/10.1175/2008MWR2653.1.

— and - 2011: A new bulk microphysical scheme that includes riming intensity and temperature-dependent ice characteristics. Mon. Wea. Rev., 139, 1013-1035, https://doi.org/ 10.1175/2010MWR3293.1.

,-- , and S. E. Yuter, 2013: Impact of moisture flux and freezing level on simulated orographic precipitation errors over the Pacific Northwest. J. Hydrometeor., 14, 140-152, https://doi.org/10.1175/JHM-D-12-019.1.

Lin, Y.-L., S. Chiao, T.-A. Wang, M. L. Kaplan, and R. P. Weglarz, 2001: Some common ingredients for heavy orographic rainfall. Wea. Forecasting, 16, 633-660, https://doi.org/10.1175/15200434(2001)016<0633:SCIFHO > 2.0.CO;2.

Liu, C., K. Ikeda, G. Thompson, R. Rasmussen, and J. Dudhia, 2011: High-resolution simulations of wintertime precipitation in the Colorado headwaters region: Sensitivity to physics parameterizations. Mon. Wea. Rev., 139, 3533-3553, https:// doi.org/10.1175/MWR-D-11-00009.1.

Mansell, E. R., 2010: On sedimentation and advection in multimoment bulk microphysics. J. Atmos. Sci., 67, 3084-3094, https://doi.org/10.1175/2010JAS3341.1.

_ C. L. Ziegler, and E. C. Bruning, 2010: Simulated electrification of a small thunderstorm with two-moment bulk microphysics. J. Atmos. Sci., 67, 171-194, https://doi.org/10.1175/ 2009JAS2965.1.

Miglietta, M. M., and R. Rotunno, 2005: Simulations of moist nearly neutral flow over a ridge. J. Atmos. Sci., 62, 1410-1427, https://doi.org/10.1175/JAS3410.1.

_ and - 2006: Further results on moist nearly neutral flow over a ridge. J. Atmos. Sci., 63, 2881-2897, https://doi.org/ 10.1175/JAS3793.1.

Minder, J. R., D. R. Durran, G. H. Roe, and A. M. Anders, 2008: The climatology of small-scale orographic precipitation over the Olympic Mountains: Patterns and processes. Quart. J. Roy. Meteor. Soc., 134, 817-839, https://doi.org/10.1002/qj.258.

Morales, A., H. Morrison, and D. J. Posselt, 2018: Orographic precipitation response to microphysical parameter perturbations for idealized moist nearly neutral flow. J. Atmos. Sci., $\mathbf{7 5}$, 1933-1953, https://doi.org/10.1175/JAS-D-17-0389.1.

Morris, M. D., 1991: Factorial sampling plans for preliminary computational experiments. Technometrics, 33, 161-174, https:// doi.org/10.1080/00401706.1991.10484804.

Morrison, H., J. A. Curry, and V. I. Khvorostyanov, 2005: A new double-moment microphysics parameterization for application in cloud and climate models. Part I: Description. J. Atmos. Sci., 62, 1665-1677, https://doi.org/10.1175/JAS3446.1.

— G. Thompson, and V. Tatarskii, 2009: Impact of cloud microphysics on the development of trailing stratiform precipitation in a simulated squall line: Comparison of one- and two-moment schemes. Mon. Wea. Rev., 137, 991-1007, https:// doi.org/10.1175/2008MWR2556.1.

, J. A. Milbrandt, G. H. Bryan, K. Ikeda, S. A. Tessendorf, and G. Thompson, 2015: Parameterization of cloud microphysics based on the prediction of bulk ice particle properties. Part II: Case study comparisons with observations and other schemes. J. Atmos. Sci., 72, 312-339, https://doi.org/10.1175/JAS-D-140066.1. 
Neiman, P. J., L. J. Schick, F. M. Ralph, M. Hughes, and G. A. Wick, 2011: Flooding in western Washington: The connection to atmospheric rivers. J. Hydrometeor., 12, 1337-1358, https:// doi.org/10.1175/2011JHM1358.1.

Purdy, J. C., G. L. Austin, A. W. Seed, and I. D. Cluckie, 2005: Radar evidence of orographic enhancement due to the seeder feeder mechanism. Meteor. Appl., 12, 199-206, https://doi.org/ 10.1017/S1350482705001672.

Ralph, F. M., and M. D. Dettinger, 2011: Storms, floods, and the science of atmospheric rivers. Eos, Trans. Amer. Geophys. Union, 92, 265266, https://doi.org/10.1029/2011EO320001.

_ , P. J. Neiman, and G. A. Wick, 2004: Satellite and CALJET aircraft observations of atmospheric rivers over the eastern North Pacific Ocean during the winter of 1997/98. Mon. Wea Rev., 132, 1721-1745, https://doi.org/10.1175/1520-0493(2004) $132<1721$ :SACAOO $>2.0 . C O ; 2$.

- , - and R. Rotunno, 2005: Dropsonde observations in lowlevel jets over the northeastern Pacific Ocean from CALJET-1998 and PACJET-2001: Mean vertical-profile and atmospheric-river characteristics. Mon. Wea. Rev., 133, 889910, https://doi.org/10.1175/MWR2896.1.

— - , G. A. Wick, S. I. Gutman, M. D. Dettinger, D. R. Cayan, and A. B. White, 2006: Flooding on California's Russian River: Role of atmospheric rivers. Geophys. Res. Lett., 33, L13801, https://doi.org/10.1029/2006GL026689.

Saltelli, A., and Coauthors, 2008: Global Sensitivity Analysis: The Primer. John Wiley and Sons Ltd., 305 pp.

Schwartz, C. S., and Coauthors, 2010: Toward improved convection-allowed ensembles: Model physics sensitivities and optimizing probabilistic guidance with small ensemble membership. Wea. Forecasting, 25, 263-280, https://doi.org/ 10.1175/2009WAF2222267.1.

Shin, M.-J., J. H. A. Guillaume, B. F. W. Croke, and A. J. Jakeman, 2013: Addressing ten questions about conceptual rainfall-runoff models with global sensitivity analyses in R. J. Hydrol., 503, 135152, https://doi.org/10.1016/j.jhydrol.2013.08.047.

Song, C., J. Zhang, C. Zhan, Y. Xuan, M. Ye, and C. Xu, 2015: Global sensitivity analysis in hydrological modeling: Review of concepts, methods, theoretical framework, and applications. J. Hydrol., 523, 739-757, https://doi.org/10.1016/ j.jhydrol.2015.02.013.

Thompson, G., P. R. Field, R. M. Rasmussen, and W. D. Hall, 2008: Explicit forecasts of winter precipitation using an improved bulk microphysics scheme. Part II: Implementation of a new snow parameterization. Mon. Wea. Rev., 136, 5095-5115, https://doi.org/10.1175/2008MWR2387.1.

Tushaus, S. A., D. J. Posselt, M. M. Miglietta, R. Rotunno, and L. Delle Monache, 2015: Bayesian exploration of multivariate orographic precipitation sensitivity for moist stable and neutral flows. Mon. Wea. Rev., 143, 4459-4475, https://doi.org/ 10.1175/MWR-D-15-0036.1.

Xue, M., and Coauthors, 2009: CAPS realtime multi-model convection-allowing ensemble and $1-\mathrm{km}$ convectionresolving forecasts for the NOAA Hazardous Weather Testbed 2009 Spring Experiment. 23rd Conf. on Weather Analysis and Forecasting/19th Conf. on Numerical Weather Prediction, Omaha, NE, Amer. Meteor. Soc., 16A.2, https://ams.confex.com/ams/23WAF19NWP/techprogram/ paper_154323.htm.

Yang, J., F. Castelli, and Y. Chen, 2014: Multiobjective sensitivity analysis and optimization of distributed hydrologic model MOBIDIC. Hydrol. Earth Syst. Sci., 18, 4104-4112, https:// doi.org/10.5194/hess-18-4101-2014.

Zarzycki, C. M., and P. A. Ullrich, 2017: Assessing sensitivities in algorithmic detection of tropical cyclones in climate data. Geophys. Res. Lett., 44, 1141-1149, https://doi.org/10.1002/ 2016GL071606.

Zhang, T., L. Li, Y. Lin, W. Xue, F. Xie, H. Xu, and X. Huang, 2015: An automatic and effective parameter optimization method for model tuning. Geosci. Model Dev., 8, 3579-3591, https://doi.org/10.5194/gmd-8-3579-2015.

Ziegler, C. L., 1985: Retrieval of thermal and microphysical variables in observed convective storms. Part 1: Model development and preliminary testing. J. Atmos. Sci., 42, 14871509, https://doi.org/10.1175/1520-0469(1985)042<1487: ROTAMV $>2.0 . \mathrm{CO} ; 2$. 